\title{
Causal Inference in Population Trends: Searching for Demographic Anomalies in Big Data
}

\author{
Mathew E. Hauer \\ Department of Sociology, Florida State University \\ and \\ Stephanie A. Bohon \\ Department of Sociology, University of Tennessee - Knoxville
}

November 19, 2020

\begin{abstract}
The proliferation of big data, wider access to advanced computing platforms, and the development of powerful statistical algorithms can uncover hidden anomalies in social data, previously dismissed as noise. Here, we combine causal inference techniques and abductive reasoning to identify fertility and mortality anomalies on twenty years of complete demographic data in the United States. We uncover real, "hidden" baby booms/busts and mortality spikes/dips, distinguishable from regular trend variations. We identify more than 22 and 156 fertility and mortality anomalies, totaling more than $200 \mathrm{k}$ and $600 \mathrm{k}$ anomalous births and deaths, respectively. Notable detectable mortality anomalies include the September 112001 terrorist attack in New York and the emergence and acceleration of the opioid epidemic in New Hampshire. Notable fertility anomalies include the "missing births" in Louisiana after Hurricane Katrina and the reduction in fertility behavior after the September 2008 stock market crash in Connecticut, amongst others. The combined causal inference and abductive reasoning approach can be readily adapted to find other, undiscovered social phenomena or to evaluate the efficacy of important public policies.
\end{abstract}

Keywords: mortality, fertility, causal inference, abductive reasoning, big data 


\section{Introduction}

The search for causality is one of the primary motivations of social scientists Smith 2011, Pearl et al. 2009). Causal inference, the identification of causal mechanisms, attempts to uncover the underlying mechanisms that result in changes in a phenomenon and has a long history as an approach to inquiry in the social sciences (Grimmer 2015). Often, the identification of a casual mechanism is accomplished via a randomized control trial (RCT) or expert knowledge applied to a natural experiment (Salganik 2019).

Unfortunately, both RCTs and natural experiments have drawbacks. RCTs are often prohibitively expensive for many scientists, precluding their widespread adoption in the social sciences (West et al. 2008). RCTs are also sometimes impossible to deploy in the "real world." For instance, an RCT to study country-level austerity measures would be difficult, if not impossible, to implement. RCTs to study fertility would be immoral. Natural experiments are a cheaper alternative but provide less certainty about causation, fewer opportunities to replicate work, and require expert knowledge of the natural experiment to be properly employed (Pearl \& Mackenzie 2018).

Additionally, both RCTs and natural experiments are based on traditional hypothesisbased testing, the deductive scientific paradigm where a question is first posed and scientists generate or find data to answer the question. Such approaches, while extensively utilized and time-tested, increase the likelihood that a researcher will miss important phenomena that might go unnoticed because it falls outside the hypothesis, or the study could suffer from extensive p-hacking (Head et al. 2015, Nuzzo 2014, Ruggles 2014). At the same time, purely inductive data mining can result in false assertions or spurious findings, especially in the hands of those who are not field experts (Yanai \& Lercher 2020). Abductive reasoning, sometimes described as "inferring cause from effect" (Crowder \& Carbone 2017), moves the scientific process from the inductive to the deductive, and sometimes back and forth, to reach conclusions (Bryant \& Raja 2014). Physical scientists use abductive reasoning more commonly than social scientists. The discovery of Neptune in 1846 based on unexplained perturbations of the orbit of Uranus (Popper 2005), the discovery of galactic migration of planets (Gomes et al.2005), and the current generation of gravitational wave detectors such as the Laser Interferometer Gravitational-Wave Observatory (LIGO) (Harry et al. 2010) 
demonstrate the power of the abductive approach in the physical sciences.

In a data-rich environment, abductive reasoning can be more easily applied to first find effects and then infer their cause ex-post. The modern proliferation of data, advances in high performance ("super") computing, and the development of powerful statistical algorithms provide an environment ripe for wedding causal inference with abductive reasoning (Van Der Aalst 2016, Zikopoulos \& Eaton 2011), with the potential for researchers to find hidden or understudied social phenomena (Bohon 2018). While the availability of big data and high performance computing allows novel exploration of data through causal inference (Bohon 2018, Brodersen et al. 2014, Shiffrin 2016), relatively few studies utilize causal inference techniques in the study of demographic phenomena. However, understanding social phenomena using these advances reveals important insights into society (Angrist et al. 1989, Mas \& Moretti 2009) and allows us to better monitor population trends Nobles \& Seltzer 2019, Torche \& Shwed 2015). The rich demographic data available in the United States make the potential revelation of interesting and important demographic phenomena not only possible, but extremely plausible - even if identification of the phenomena occurs without identifying the underlying cause.

In this paper, we combine a modern statistical outlier detection algorithm Chen \& Liu 1993), abductive reasoning, and large demographic data sets on more than 20 years of mortality and fertility trends to identify anomalous demographic behavior. In essence, we identify effects without knowledge of the cause. We ask one fundamental question regarding demographic anomalies: What are the hidden baby booms/busts and mortality spikes/dips in the United States over the last twenty years? We do not necessarily know the causes of these anomalies and suggest causes for select anomalies. Even without knoweldge of the causes, simply identification of anomalies allows scientists with more detailed knowledge of local population dynamics, state-level policy making, or macro-economics to explain these phenomena post-hoc. From explanations of phenomena that may have previously gone unnoticed, social scientists may be able to better forecast populations and provide policy solutions for impending problems such as climate change. 


\section{Abductive Reasoning and Causal Inference}

Scientific inquiry falls under one of three modes of logical reasoning: deduction, induction, and abduction. Deductive reasoning starts with a theory and makes a prediction of what the observations should be if that theory is correct. The classic example of deductive reasoning essentially goes (a) "all men are mortal," (b) "Socrates is a man," (c) "therefore, Socrates is mortal." Deductive reasoning has a long history in the sciences and most hypothesis testing in the social sciences follows this logical reasoning. For example, John Snow used deductive reasoning to stop the 1854 London cholera outbreak. He hypothesized that cholera was waterborne and deduced that a bad water pump was responsible for the outbreak.

Inductive reasoning is directionally opposite of deductive reasoning. Rather than starting with a theory and making a prediction, induction starts with an observation and makes a theory based on the likeliest reason. For example, the Hispanic Mortality Paradox first appeared in the scientific literature in the mid-1980s (Markides \& Coreil 1986) as an observation that Hispanics in the United States had better health outcomes than expected given their socioeconomic status. Based on this observation, numerous theories arose to explain this paradox.

Both deductive and inductive reasoning are well established in science but are not without their shortcomings. In both approaches, it is impossible, or at least improbable, for the premise to be true and the conclusion false. Furthermore, if a hypothesis is rejected under a deductive or inductive approach, there is no alternative explanation - there is either the presence or absence of support.

Abductive reasoning is a third, less well-known way that reasons the best explanation given the observations (Walton 2014). It is most concerned with generating and evaluating explanatory hypotheses (Crowder \& Carbone 2017) by looking for a pattern and suggesting a hypothesis $($ Fann 2012, Pierce 1878). Unlike the more rigid deductive and inductive reasoning, abductive reasoning allows the scientist to move between deduction and induction and fits well during exploratory data analysis ( $\mathrm{Yu}$ 1994, Haig 2015, Tukey 1977). During exploratory data analysis, abductive reasoning helps find a pattern and suggest a hypothesis, deduction helps refine and build a testable hypothesis, and induction is the empirical 
support (Yu| 1994$)$.

Abductive reasoning and exploratory data analysis are best employed in a data rich environment - the very data environment social scientists and demographers find themselves in the present moment. In a data rich environment, a hypothesis is a hidden liability (Yanai \& Lercher 2020) because it focuses our attention on only that which we seek. To demonstrate this, 11. Focusing on specific hypotheses often prevents us from finding other interesting phenomena. After all, it was the publication of the Hispanic paradox itself that has generated more than thirty years of devoted scholarship. At the same time, when paired with causal inference techniques, abductive reasoning provides an empirical platform for the discovery of potentially interesting social phenomena; it provides an important tool for sifting large amounts of data to find interesting results without the blinders of hypothesis testing.

\section{Materials and Methods}

\subsection{Method}

We use a statistical time series outlier detection algorithm (Chen \& Liu 1993), implemented in the $\mathrm{R}$ programming language ( $\mathrm{R}$ Core Team 2019) via the tsoutliers package (Lópezde-Lacalle 2019). This algorithm iteratively uses ARIMA models to 1) identify potential outliers or anomalies and 2) refit the ARIMA with the outliers removed to produce a counter-factual time series. Here we briefly summarize and describe the method.

Often, the behavior of a time series can be described and summarized in ARIMA models. If a series of values, $y_{t}^{*}$, is subject to $m$ interventions or outliers at time points $t_{1}, t_{2}, \ldots, t_{m}$ with weights $\omega$ then $y_{t}^{*}$ can be defined as

$$
y_{t}^{*}=\sum_{j=1}^{m} \omega_{j} L_{j}(B) I_{t}\left(t_{j}\right)+\frac{\theta(B)}{\phi(B) \alpha(B)} \alpha_{t}
$$

\footnotetext{
${ }^{1}$ Yanai and Lercher (2020) ask if focusing on a specific hypothesis prevents new discovery. By way of illustration, they created a simple dataset that if plotted would reveal an image of a gorilla waving. Students instructed to find support for specific hypotheses were less likely to discover the gorilla compared to those who were simply asked "What do you conclude from the dataset?"
} 
Where $I_{t}\left(t_{j}\right)$ is an indicator variable with a value of 1 at observation $t_{j}$ and where the $j$ th outlier arises, $\phi(B)$ is an autoregressive polynomial with all roots outside the unit circle, $\theta(B)$ is a moving average polynomial with all roots outside the unit circle, and $\alpha(B)$ is an autoregressive polynomial with all roots on the unit circle.

We examine three types of outliers at time point $t_{m}$ :

1. additive outliers $(\mathrm{AO})$, defined as $L_{j}(B)=1$;

2. level shift outliers (LS), defined as $L_{j}(B)=1 /(1-B)$; and

3. temporary change outliers (TC), defined as $L_{j}(B)=1 /(1-\delta B)$ where $\delta$ is equal to 0.7 .

Colloquially, additive outliers arise when a single event causes the time series to unexpectedly increase/decrease for a single time period; level shift outliers arise when an event causes the time series to unexpectedly increase/decrease for multiple time periods; and temporary change outliers arise when an event causes the time series to unexpectedly increase/decrease with lingering effects that decay over multiple time periods.

An outlier is detected with the estimated residuals using a regression equation

$$
\pi(B) y_{t}^{*} \equiv \hat{e}=\sum_{j=1}^{m} \omega_{j} \pi(B) L_{j}(B) I_{t}\left(t_{j}\right)+\alpha_{t}
$$

where $\pi(B)=\sum_{i=o}^{i n f} \pi_{i} B^{i}$.

Equations 1 and 2 allow for an automatic detection of anomalies iterated over a twostage process.

In stage 1, anomalies are located. First, an ARIMA model is fit to the time series using the forecast package in R (Hyndman et al. 2019, Hyndman \& Khandakar 2008) where the best performing ARIMA model is selected based on the Bayesian information criterion (BIC). Next, the residuals from the forecast are checked for their significance using equation 2 where only anomalies above a critical $t$-static are considered "true" anomalies $(|\tau| \geq$ 3.5). We choose this critical value based on Chen and Liu's (1993) recommendation to minimize Type I or false-positive anomalies. Finally, two additional rules are implemented: If multiple anomalies are detected at the same time point, only the most significant anomaly is selected and if anomalies of the same type at consecutive time periods are detected, only the anomaly with highest $t$-statistic is selected. 
In stage 2, anomalies are removed from the time series and a new ARIMA model is chosen and fit. The selection of the initial ARIMA model could have been affected by the presence of the anomalies, making some anomalies spuriously identified. To correct for this, a new ARIMA model is fit accounting for additional regression effects in equation 1 from the list of candidate anomalies identified in stage 1, effectively removing the anomalies from the time series. Each anomaly is then reassessed under the new model and those anomalies that are no longer significant are removed.

These two stages are then iterated until no additional anomalies are detected.

\subsection{Robustness Check}

To determine the false-positive (Type I) and false-negative (Type II) error rates under a critical value of 3.5, we ran two simulations. For the false-positive error we simulated 1000 time series with 180 time steps without introducing any anomalies and ran the tsoutliers algorithm on them. Any anomalies we detect in these time series are spurious anomalies. For the false-negative error, we simulated 1000 time series with 180 time steps but introduced a single anomaly of the same magnitude at the same time point in each time series. If the tsoutliers algorithm fails to detect the anomaly, it would be considered a false-negative error.

In our sans-anomaly time series, we detect 208 anomalies on the 180,000 candidate time steps for a false-positive error rate of $0.116 \%$. In our time series containing a single anomaly, we detect 817 anomalies out of the 1000 candidate time series, for a false-negative error rate of $18.3 \%$. This provides a statistical power of 0.817 . These results give us confidence that the anomalies we detect in this paper are true anomalies.

\subsection{Toy example}

Figure 1 shows a toy example for anomaly detection in a time series using the classic example of the exchange rate between the Euro and the Swiss Franc (CHF). On January 15 2015, the Swiss National Bank removed the currency peg of 1.20 francs per Euro, exposing the Franc to the volatility of the currency market. The Franc immediately began trading

a reduced rate compared to the Euro. What would have been the Euro/CHF exchange 


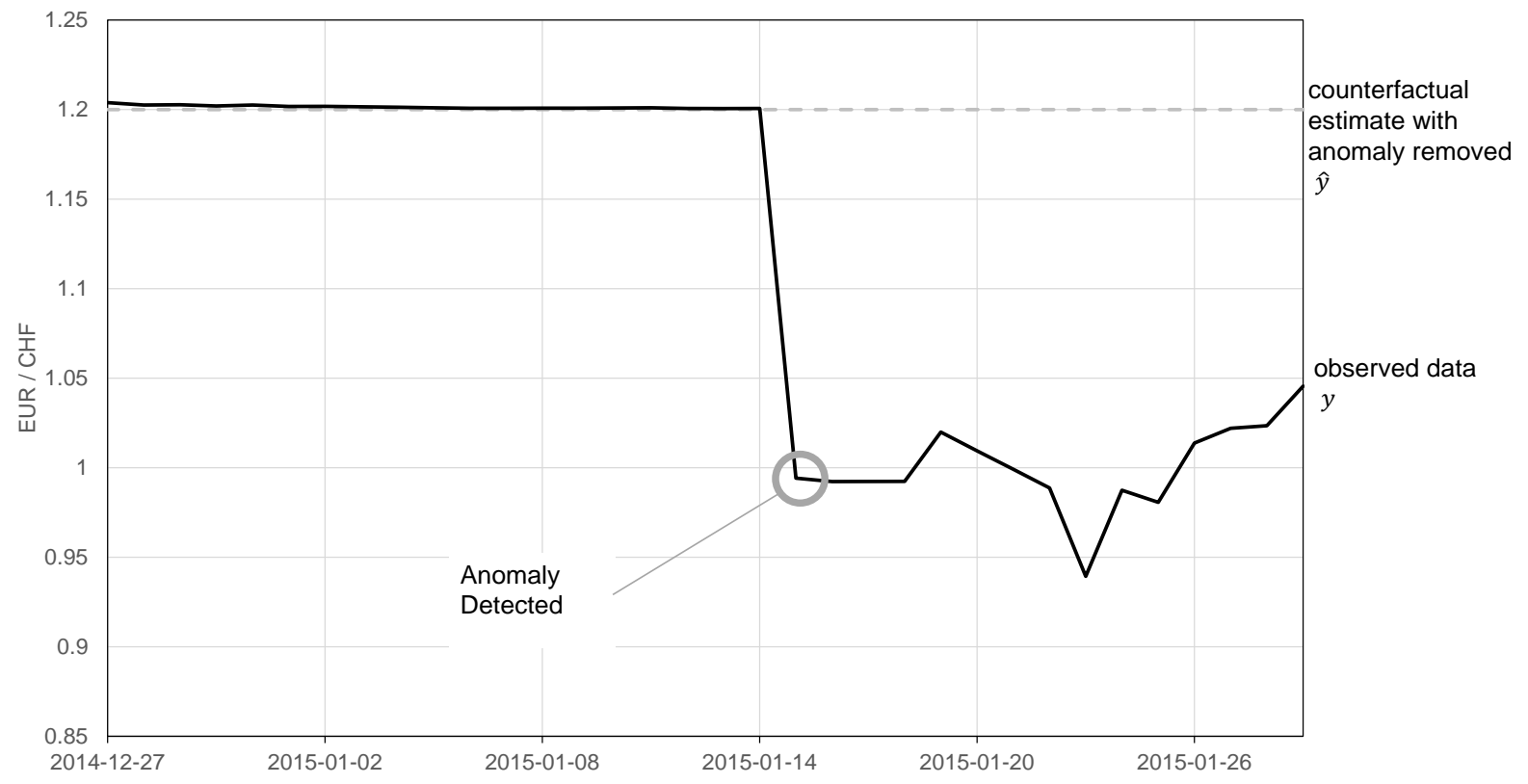

Figure 1: "Toy" example of anomaly detection using the exchange rate between the Euro and the Swiss Franc. The Swiss Franc was pegged to the Euro at 1.2 until January 152015 when the peg was removed and the currency was allowed to trade more freely. This is a very strong anomly in the time series $(t$-stat $=-144.07)$ detectable using statistical methods and visually. The countefactural estimate with the outlier removed would simply have kept the currency exchange at $1.2(\hat{y})$. 
rate had the Swiss National Bank not removed the peg? A simple counter-factual estimate would be to keep the exchange rate at 1.20 ( $\hat{y}$, sometimes called a "synthetic control" (Abadie et al. 2010).

In the Swiss Franc example, we have knowledge of the Swiss Bank's activities after the fact or ex-post-facto to to create the counter-factual time series $\hat{y}$ of 1.20. But is this anomaly detectable without knowledge of the Swiss Bank's activities? In other words, can we detect the reduction of the exchange rate on January 15 using only the time series? Absolutely. the tsoutliers package identifies January 152015 as an extremely strong levelshift outlier $(t$-stat $=-144.07)$. The real world is hardly this simplified where a direct intervention is known and is testable.

\subsection{Data}

We search for demographic anomalies using the Center for Disease Control and Prevention's online WONDER monthly fertility (2003-2017) and mortality databases (1999-2016) for all fifty states and the District of Columbia (United States Department of Health and Human Services (US DHHS), Centers for Disease Control and Prevention (CDC) 2018, Centers for Disease Control and Prevention, National Center for Health Statistics. 2019). These data sets contain every birth and death record in the United States over the time periods of interest, representing the universe of both mortality and fertility data in the US. These data are considered the "gold standard" of data collections (Mahapatra et al. 2007) and have been considered "complete" since 1968 (Hetzel 2016). We search over each state equivalent's $(\mathrm{n}=51)$ mortality $(\mathrm{n}=228)$ and fertility $(\mathrm{n}=180)$ monthly time series for a total of 20,808 state-months of data.

\subsection{Replication Files}

All data and code necessary to reproduce the reported results are licensed under the CC-BY-4.0 license and are publicly available as https://osf.io/yc3r4/?view_only= 3ce3ca267c7047e0942940ebd08846d0. The analyses were performed in $R$ ( $\mathrm{R}$ Core Team 2019). 


\section{Results}

We detect numerous anomalous mortality and fertility events at the US state-level since 1999. A full listing of these anomalies can be found in the Supplementary Materials. We begin by highlighting significant fertility and mortality anomalies across all three types of outliers (Additive Outliers, Level Shift Outliers, and Temporary Change outliers) with plausible explanations. We then highlight two strong anomalies that bely explanation. Finally, we conclude with a summary of the anomalies we detect.

\subsection{Fertility}

We begin with a clear temporary change (TC) outlier for fertility in Louisiana (Figure 2a). Here we detect two TC outliers, nearly back-to-back in 2005 (2005:08 $t=-6.002$; and 2005:10 $t=-4.997)$, coinciding with the destruction of Hurricane Katrina from the same year. The migration associated with Hurricane Katrina has garnered most of the attention of social scientists (Fussell et al. 2014, Hori et al. 2009), but the hurricane had a very clear impact on fertility behaviors too, creating a mini "baby bust" in Louisiana with the departure of many people in their childbearing years. We estimate 4,411 fewer births in Louisiana compared to the counter-factual, likely attributable to the Hurricane.

We also highlight a level shift (LS) outlier for fertility in Connecticut. Here we detect a strong $(t=-3.71$ for -285 births/month) level shift toward lower fertility beginning in August 2009 (2009:08) that continues through the end of the period (Figure 2 b). This LS toward lower fertility reduced the number of births by 28,752 or $9 \%$ ) lower than the counter-factual time series. The stock market crash of 2008, where the Dow Jones Industrial Average had the largest single-day loss up to that point, occurred just 11 months before we detect a shift toward lower fertility. It is possible that the trend toward lower fertility in August 2009 and the stock market crash in September 2008 are linked, although, as stated previously, we are speculating only to illustrate how causal inference could work in an abductive research agenda. A potentially interesting future line of research would be to link fertility anomalies to the kinds of economic shocks that may lead to out-migration of those in their childbearing years. 
a

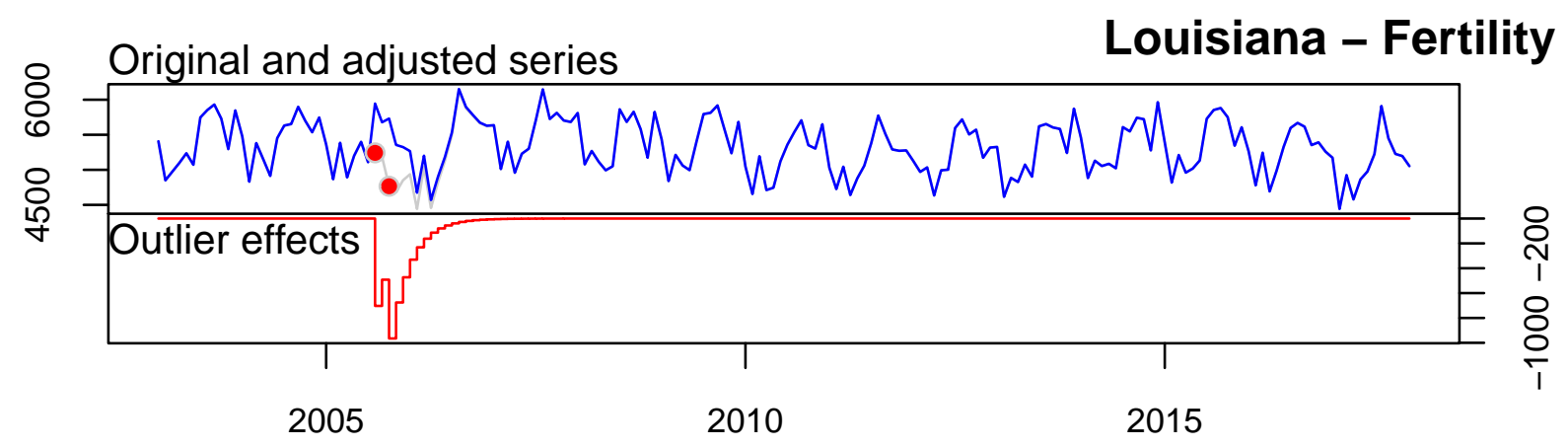

b

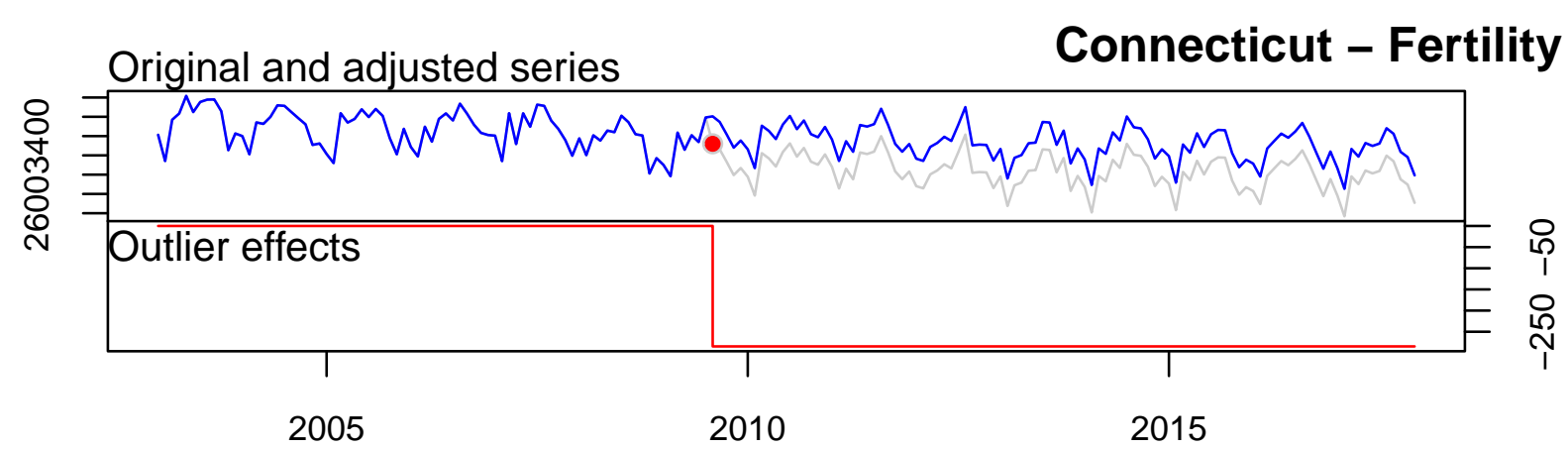

Figure 2: Anomaly detection in Louisiana (a) and Connecticut (b) state fertility, 2003-2018. The top part of each panel contains the original time series (light gray), the corrected, counter-factual time series in the absence of anomalies (blue), and the red dots correspond to the onset of detected anomalies. The bottom part of each panel contains the magnitude and type of the outlier in red. In (a), we detect two outliers, back-to-back, likely resulting from Hurricane Katrina in August and October 2005, representing a decrease of more than 4,400 births due to the hurricane (t-statistics=-6.002 and -4.997). In (b), we detect one outlier, a level shift outlier (LS) in August 2009. We believe this reduction is attributable to the stock market crash 11 months earlier $($ t-statistic $=-3.71)$. 


\subsection{Mortality}

For mortality, we will use New York State as an example (Figure 3a). We identify seven anomalies in the mortality time series for New York, all with $t$-statistics in excess of 3.91, making these anomalies unlikely to be due to chance. The algorithm correctly identifies September 2001 as an additive outlier (2001:09 $t=6.396)$ where there were 1,628 more deaths in that month than anticipated. This mortality event is likely caused by the September 11 terrorist attack on the World Trade Center that immediately killed 2,606 people and the detection of this mortality event provides confidence in our detection of other anomalies.

In Figure 3a, notice the strong level shift (LS) that occurs in February 2004 (2004:02 $t=-5.594)$ which prevented 869 deaths per month. This shift totals more than 144,000 averted deaths compared to the counter-factual time series and is the single largest mortality protective anomaly among all states. This translates to $7 \%$ fewer deaths than expected over the time period. What is driving this mortality protection? What policies did NY put into place that might have contributed to this considerable mortality reduction? What environmental or economic conditions may have changed? These are the kinds of questions that arise from our analyses. The purpose of our paper is not to answer these questions, but our findings underscore the need for more research that takes an abductive approach. By identifying anomalies through an inductive process, researchers can then look for underlying causes. Once those causes are identified, researchers can then use a deductive process to see if such events predict other (or future) anomalies.

To see the potential for combining abductive reasoning with causal inference, contrast the mortality protection in New York with the enhanced mortality in New Hampshire (Figure 3b). In New Hampshire we detect two significant level shifts (LS) in the monthly mortality data, first in April 2010 and again in November 2014 (2010:04 $t=3.51$; 2014:11 $t=6.68)$. These anomalies suggest New Hampshire experienced 8,159 more deaths $(+9 \%$ more than expected) in a seven-year period beginning in early 2010. These are events not experienced by neighboring states during the same time period, and this is the single largest percentage mortality increase/decrease we detected among all states. Not coincidentally, NH has the second highest opioid-related mortality in the US (Beetham et al. 2019) and it is likely that we detect this epidemic in our results. Isolating these anomalies and testing 
them against opioid sales data might yield intriguing results.

\subsection{Interesting Anomalous Fertility/Mortality events}

In the examples above, we highlighted four fertility/mortality anomalies with plausible explanations. In the case of New York and New Hampshire, the mortality anomalies have plausible explanations. It seems likely that New York's AO anomaly in September 2001 is caused by the 9/11 tragedy and the rise in New Hampshire's mortality starting in 2010 could be linked to the opioid epidemic. Similarly, Louisiana's TC anomalies seem linked to Hurricanes Katrina and Rita while the LS anomaly in Connecticut's fertility appears linked to the Great Recession. However, we detect numerous other demographic anomalies in other states, on the causes of which we will not speculate. Figure 4 shows two such unexplained anomalies.

In Figure 4a we identify a single additive anomaly in Hawaiian fertility in May 2014. This is a strong anomaly with a $t$-statistic of 4.96, $15 \%$ above the counter-factual time series. This single, anomalous month is also the second highest monthly births in the time series. We have no plausible explanation for this anomaly. We do not believe this is simply a data error as the other extreme values, September 2008 and February 2005 with the

highest and lowest recorded fertility respectively, were not identified as anomalous events. Even if we were to assume this anomaly resulted from data entry error, it remains an unaltered data error in the Hawaiian monthly fertility data.

This is contrast to Figure $\mathbf{4} \mathbf{b}$, where we identify a strange mortality reduction in Ohio ( $t$-stat: -4.27$)$. This LS is more than 1,157 deaths per month less than the counterfactual time series, suggesting Ohio had nearly 40,000 fewer deaths since February 2015 than expected. This is the single-largest LS among all states. We could not identify the potential policies Ohio might have put into place or the events that occurred to provide such a strong mortality protection.

\subsection{Overall Anomalies}

Table 1 reports the overall number of anomalies we detect of each type for births and deaths and some summary statistics across all anomaly types and Figure 5 maps these 

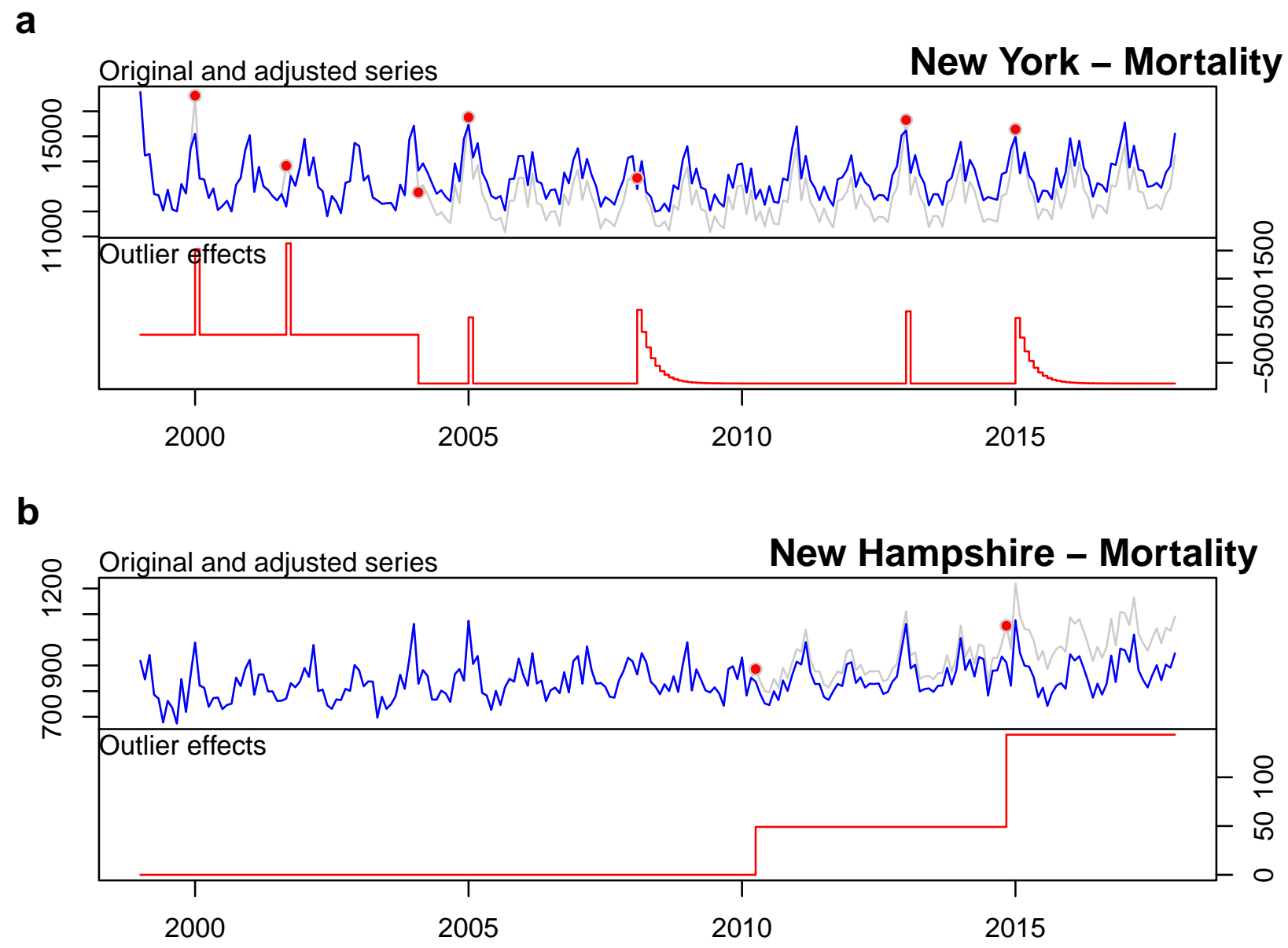

Figure 3: Anomaly Detection for New York (a) and New Hampshire (b) state mortality, 1999-2016. In New York (a), we detect additive outliers (AO) in January 2000, September 2001, January 2005, and January 2013; temporary change (TC) outliers in February 2007 and January 2015; and a level shift (LS) starting in February 2004. In New Hampshire (b), we detect two outliers, both level shift outliers (LS) in April 2010 and again in November 2014. These anomalies suggest New York experienced a significant mortality event in September 2001 and New Hampshire experienced approximately 9,700 more deaths than expected since 2010 or $14 \%$ more deaths in the state over just seven years. 
a

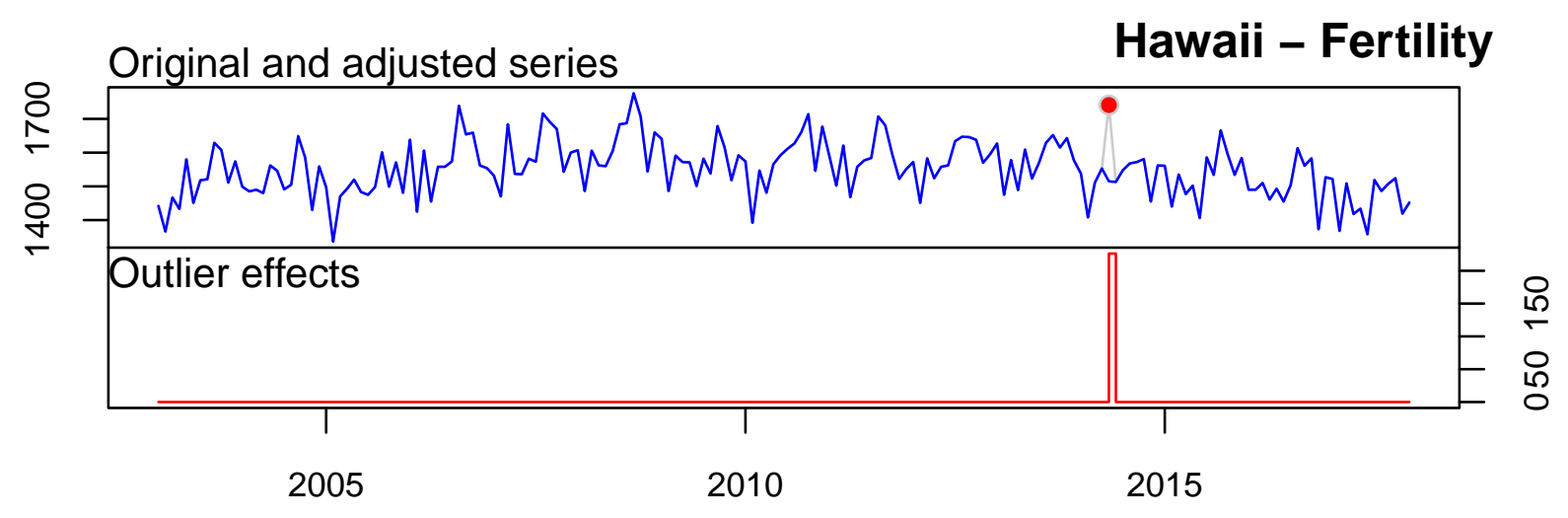

b

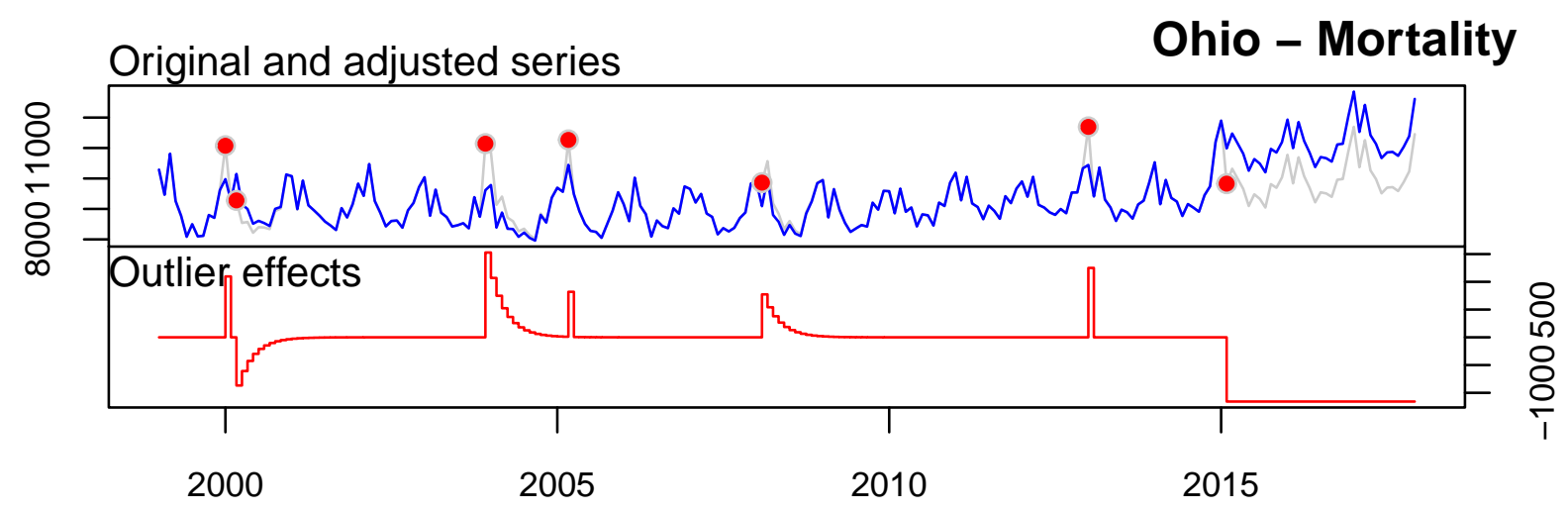

Figure 4: Anomaly detection in Hawaii state fertility (a) and Ohio state mortality (b). Here we detect one outlier, an additive outlier (AO) in May 2014 in Hawaii (a), representing a large, unexplainable $14 \%$ increase in expected births in that month. We also detect a strong level shift (LS) reduction (b), representing a large, unexplainable reduction of nearly 40,000 deaths in Ohio. 
Table 1: Summary by Demographic Component. Here we can see there 22 Fertility and 156 Mortality anomalies among the state-level time series, totalling more than 200k anomalous births and 600k anomalous deaths.

\begin{tabular}{lrllrrr}
\hline Component & Anomalies & $y$ & $\hat{y}$ & $y-\hat{y}$ & $|y-\hat{y}|$ & $\%$ of Total \\
\hline Fertility & 22 & $25.48 \mathrm{M}$ & $25.68 \mathrm{M}$ & $-202,217$ & 226,476 & 0.889 \\
Mortality & 156 & $43.57 \mathrm{M}$ & $43.52 \mathrm{M}$ & 48,535 & 627,364 & 1.440 \\
\hline
\end{tabular}

results.

We find considerably more mortality anomalies $(\mathrm{n}=156)$ than fertility anomalies $(\mathrm{n}$ $=22$ ). Given that anomalies are always the product of events (Song et al. 2018), finding more mortality than fertility anomalies is not surprising. Mortality is likely to spike in response to a catastrophic event (like an earthquake or terrorist attack) or due to a disease outbreak while the effects of a catastrophic event on fertility is less predictable. One reason for this is that fertility is linked to human decision-making more directly than mortality (Stein et al. 2014) which results in more varied outcomes, so, for example, researchers find that catastrophic weather events can increase childbearing among those who already have a child, but not among the childless (Evans et al.2010). Some events, like the 1995 Oklahoma City bombings, resulted in both fertility and mortality changes. However, changes in fertility manifest over a longer time horizon after an event, and the relationship between a fertility-inducing event and behavior change is less strong than the relationship between a mortality-inducing event (such as a terrorist incident) and death (Rodgers et al. 2005). Of course, not all events that impact fertility and mortality are catastrophic. Researchers have documented that more commonplace events such as massive layoffs (Venkataramani et al. 2019) or policy changes (Livingston et al. 2018) can also create anomalies in mortality patterns, but we have not found such evidence for fertility.

Consistent with more anomalies across the time series, we find more anomalous deaths $(627,364)$ than anomalous births $(226,476)$. Fertility anomalies overwhelmingly tend toward lower fertility, with only a few fertility anomalies yielding more births. This is consistent with research findings that link severe weather events to significantly lower fertility (Evans 
et al. 2010). Conversely, mortality anomalies tend to be more evenly split between positive and negative anomalies, but tend toward more deaths rather than fewer deaths. Again, this is not surprising, as the kinds of events that increase death (e.g., plant closings are associated with increased opioid death (Venkataramani et al. 2019)) are more common than the events that decrease death (e.g., cannabis legalization is associated with decreased opioid deaths (Livingston et al. 2018)). These anomalous deaths and births account for $1.44 \%$ and $0.889 \%$ over the entire time series, respectively.

As Figure 5 shows, three states exhibited neither mortality nor fertility anomalies: Alaska, North Dakota, and South Dakota. Another nine states exhibited just a single anomaly (Delaware, District of Colombia, Idaho, Illinois, Kansas, Nevada, New Mexico, Utah, and Wyoming). Both New York and Massachusetts exhibited the most anomalies with nine.

\section{Conclusion}

Data scientists frequently claim that the big data revolution is a turning point in scientific discovery that will allow us to solve some of the world's most pressing problems Grimmer 2015). Social scientists are skeptical of such claims, because they better understand the complexities of the social world and know from experience that data alone are not enough to solve social problems (Bohon 2018, Grimmer 2015). Nonetheless, the increased availability of data and (more importantly, we argue) the development of advanced techniques for analyzing these data will enable important discovery (Monroe et al. 2015).

One technique that population scientists underutilize is causal inference. Causal inference, in the simplest terms, is the discovery of effects in search of a cause using big data and advanced computing algorithms (Imai et al. 2008). This inductive approach is uncommon in quantitative social science where hypothesis testing is expected, and approaches are largely deductive. However, common statistical hypothesis testing is impractical with big data, as significant $\mathrm{p}$ values are guaranteed, and such approaches do not allow us to uncover all the information that big data has to offer (Monroe et al. 2015). Here, we call for an abductive approach, where causal inference algorithms are applied to high quality data to uncover irregularities that are unlikely to be attributable to expected variations 

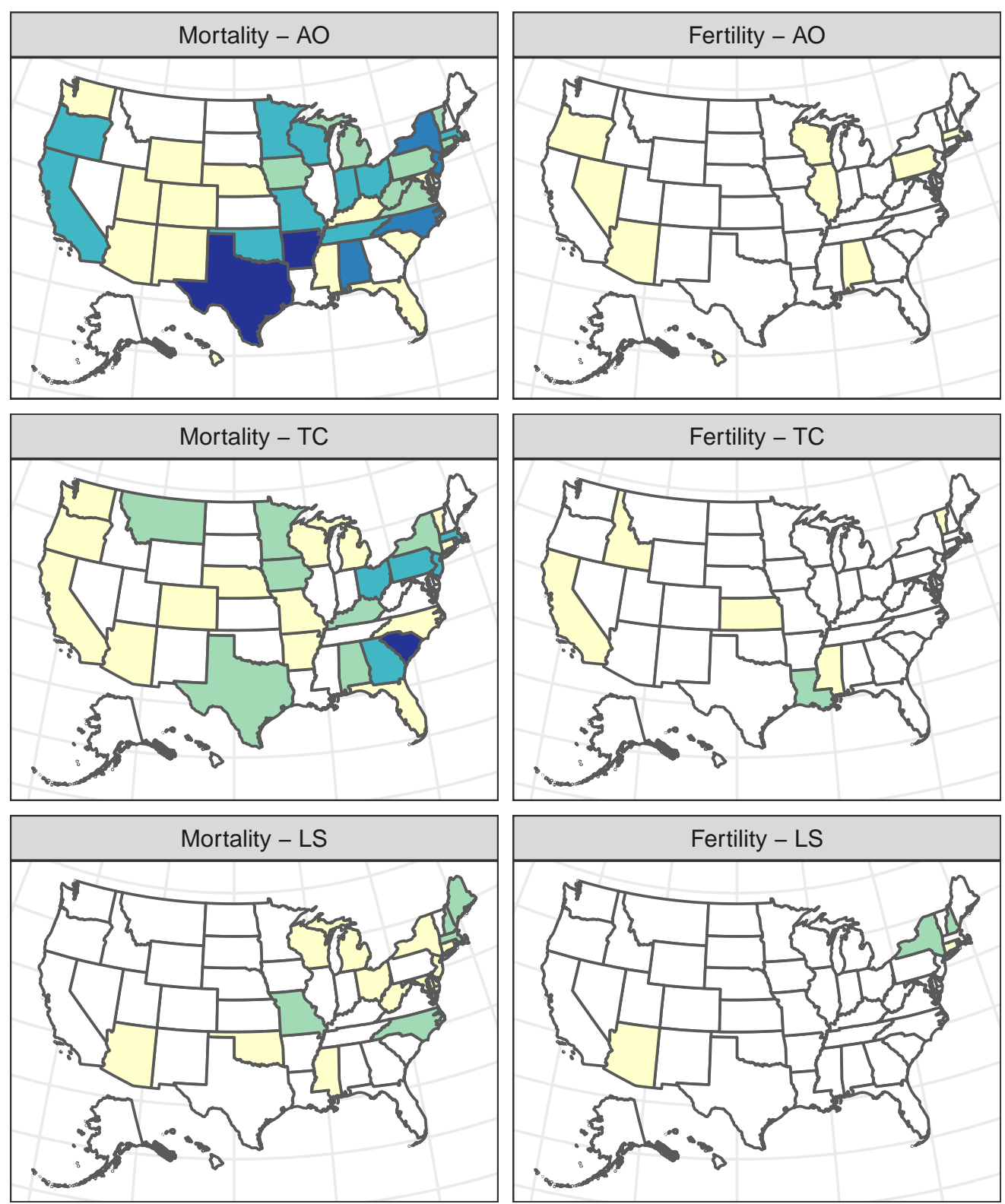

\# of Anomalies
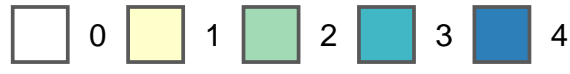

5

Figure 5: Summary of Anomalies by type, demographic component, and State. We observe much fewer fertility anomalies than mortality anomalies. 
in trends (or noise) as a first step to then developing testable hypotheses about causes. Abductive approaches allow researchers to move from the inductive to the deductive and sometimes work back and forth in aid of scientific discovery.

In this paper, we show how the tsoutlier package in $\mathrm{R}$ can be implemented to conduct statistical time series outlier detection, an inductive approach that aids in the creation of deductive reasoning. This algorithm is one of many causal inference approaches that are freely and commercially available (see Brodersen et al. (2014)). In our initial work, we experimented with other approaches, such as Google's CausalImpact algorithm, which uncovered the same patterns we briefly discuss in this paper. By making more use of causal inference techniques and abductive modeling approaches, we argue that social scientists will be able to better understand how events or policy implementation can impact important outcomes. For example, we could uncover - on a wide scale-how gun control policies may reduce or increase injuries from shootings or how marijuana legalization might impact opioid deaths. We could also uncover how increases in extreme weather events impact a range of behaviors such as home sales, bottled water purchases, and even fertility.

In our demonstration, we show how the application of causal inference to state-level time series fertility and mortality data uncovers three types of demographic anomalies: those that occur and disappear quickly, those that occur and decay over time, and those that occur and remain. Uncovering these anomalies in and of themselves is important. For example, the algorithm we deploy clearly shows the fertility effects of Hurricanes Katrina and Rita as well as the mortality effects of the World Trade Center collapse on September 11, 2001. The ability to identify and differentiate types of anomalies is even more important, as we can potentially see how some policies might impact outcomes permanently and some might have an effect that is short-lived. Differentiating these types gives us greater insight into short- and long-term solutions to social problems. We urge social scientists to begin to use causal inference algorithms and other big data techniques, and we hope that this demonstration will illustrate their usefulness to the social science enterprise. 


\section{References}

Abadie, A., Diamond, A. \& Hainmueller, J. (2010), 'Synthetic control methods for comparative case studies: Estimating the effect of california's tobacco control program', Journal of the American statistical Association 105(490), 493-505.

Angrist, J. D. et al. (1989), Lifetime Earnings and the Vietnam Era Draft Lottery: Evidence from Social Security Administrative Records, number 251, Industrial Relations Section, Princeton University.

Beetham, T., Saloner, B., Wakeman, S. E., Gaye, M. \& Barnett, M. L. (2019), 'Access to office-based buprenorphine treatment in areas with high rates of opioid-related mortality: An audit study', Annals of internal medicine 171(1), 1-9.

Bohon, S. A. (2018), 'Demography in the big data revolution: Changing the culture to forge new frontiers', Population Research and Policy Review 37(3), 323-341.

Brodersen, K. H., Gallusser, F., Koehler, J., Remy, N. \& Scott, S. L. (2014), 'Inferring causal impact using Bayesian structural time-series models', Annals of Applied Statistics 9, 247-274.

Bryant, A. \& Raja, U. (2014), 'In the realm of big data', First Monday 19(2).

Centers for Disease Control and Prevention, National Center for Health Statistics. (2019), 'Underlying Cause of Death 1999-2017 on CDC WONDER Online Database, released December, 2018. Data are from the Multiple Cause of Death Files, 1999-2017, as compiled from data provided by the 57 vital statistics jurisdictions through the Vital Statistics Cooperative Program', pp. Accessed at http://wonder.cdc.gov/ucd-icd10.html (data downloaded on 17 August 2019).

Chen, C. \& Liu, L.-M. (1993), 'Joint estimation of model parameters and outlier effects in time series', Journal of the American Statistical Association 88(421), 284-297.

Crowder, J. A. \& Carbone, J. N. (2017), Cognitive architectures for prognostic health management, in S. Ekwaro-Osire, A. C. Gonçalves \& F. M. Alemayehu, eds, 'Proba- 
bilistic Prognostics and Health Management of Energy Systems', Springer International Publishing, Cham, pp. 91-107.

Evans, R. W., Hu, Y. \& Zhao, Z. (2010), 'The fertility effect of catastrophe: U.s. hurricane births', Journal of Population Economics 23(1), 1-36.

Fann, K. T. (2012), Peirce's theory of abduction, Springer Science \& Business Media.

Fussell, E., Curtis, K. J. \& DeWaard, J. (2014), 'Recovery migration to the City of New Orleans after Hurricane Katrina: A migration systems approach', Population and Environment 35(3), 305-322.

Gomes, R., Levison, H. F., Tsiganis, K. \& Morbidelli, A. (2005), 'Origin of the cataclysmic Late Heavy Bombardment period of the terrestrial planets', Nature 435(7041), 466-469.

Grimmer, J. (2015), 'We Are All Social Scientists Now: How Big Data, Machine Learning, and Causal Inference Work Together', PS: Political Science \& Politics 48(1), 80-83.

Haig, B. D. (2015), 'Commentary: Exploratory data analysis', Frontiers in psychology $6,1247$.

Harry, G. M., Collaboration, L. S. et al. (2010), 'Advanced ligo: the next generation of gravitational wave detectors', Classical and Quantum Gravity 27(8), 084006.

Head, M. L., Holman, L., Lanfear, R., Kahn, A. T. \& Jennions, M. D. (2015), 'The extent and consequences of p-hacking in science', PLoS biology 13(3), e1002106.

Hetzel, A. (2016), 'US vital statistics system: Major activities and developments, 1950-95.(DHHS publication no.(PHS) 97-1003). hyattsville, MD: National center for health statistics; 1997'.

Hori, M., Schafer, M. J. \& Bowman, D. J. (2009), 'Displacement Dynamics in Southern Louisiana After Hurricanes Katrina and Rita', Population Research and Policy Review 28(1), 45-65.

Hyndman, R., Athanasopoulos, G., Bergmeir, C., Caceres, G., Chhay, L., O'Hara-Wild, M., Petropoulos, F., Razbash, S., Wang, E. \& Yasmeen, F. (2019), forecast: Forecasting 
functions for time series and linear models. R package version 8.10.

URL: http://pkg.robjhyndman.com/forecast

Hyndman, R. J. \& Khandakar, Y. (2008), 'Automatic time series forecasting: the forecast package for R', Journal of Statistical Software 26(3), 1-22.

URL: http://www.jstatsoft.org/article/view/v027i03

Imai, K., King, G. \& Stuart, E. A. (2008), 'Misunderstandings between experimentalists and observationalists about causal inference', Journal of the royal statistical society: series A (statistics in society) 171(2), 481-502.

Livingston, M. D., Barnett, T. E., Delcher, C. \& Wagenaar, A. C. (2018), 'Recreational cannabis legalization and opioid-related deaths in colorado, 2000-2015', American Journal of Public Health 107(11), 1827-1829.

López-de-Lacalle, J. (2019), Tsoutliers: Detection of Outliers in Time Series. R package version $0.6-8$.

Mahapatra, P., Shibuya, K., Lopez, A. D., Coullare, F., Notzon, F. C., Rao, C., Szreter, S. et al. (2007), 'Civil registration systems and vital statistics: Successes and missed opportunities', The Lancet 370(9599), 1653-1663.

Markides, K. S. \& Coreil, J. (1986), 'The health of hispanics in the southwestern united states: an epidemiologic paradox.', Public health reports 101(3), 253.

Mas, A. \& Moretti, E. (2009), 'Peers at work', American Economic Review 99(1), 112-45.

Monroe, B. L., Pan, J., Roberts, M. E., Sen, M. \& Sinclair, B. (2015), 'No! formal theory, causal inference, and big data are not contradictory trends in political science', $P S$ : Political Science $\&$ Politics 48(1), 71-74.

Nobles, J. \& Seltzer, N. (2019), Finding and Characterizing the Displaced: A method using administrative data, in 'Population Association of America Conference, Austin, Texas'.

Nuzzo, R. (2014), 'Scientific method: Statistical errors', Nature News 506(7487), 150. 
Pearl, J. \& Mackenzie, D. (2018), The book of why: the new science of cause and effect, Basic Books.

Pearl, J. et al. (2009), 'Causal inference in statistics: An overview', Statistics surveys 3, 96-146.

Pierce, C. (1878), 'Deduction, induction and abduction', Popular Science Monthly 13, 470782.

Popper, K. (2005), The logic of scientific discovery, Routledge.

R Core Team (2019), R: A Language and Environment for Statistical Computing, R Foundation for Statistical Computing, Vienna, Austria.

URL: https://www.R-project.org/

Rodgers, J. L., St. John, C. A. \& Coleman, R. (2005), 'Did fertility go up after the oklahoma city bombing? an analysis of births in metropolitan counties in oklahoma, 1990-1999', Demography 42, 675-692.

Ruggles, S. (2014), 'Big microdata for population research', Demography 51(1), 287-297.

Salganik, M. (2019), Bit by bit: Social research in the digital age, Princeton University Press.

Shiffrin, R. M. (2016), 'Drawing causal inference from big data', Proceedings of the National Academy of Sciences 113(27), 7308-7309.

Smith, G. D. (2011), 'Commentary: Random allocation in observational data: How small but robust effects could facilitate hypothesis-free causal inference', Epidemiology pp. 460463.

Song, F., Zhou, B., Sun, Q., Sun, W., Xia, S. \& Diao, Y. (2018), Anomaly detection and explanation discovery on event streams, in 'Proceedings of the International Workshop on Real-Time Business Intelligence and Analytics', pp. 1-5.

Stein, P., Willen, S. \& Pavetic, M. (2014), 'Couples' fertility decision-making', Demographic Research 30, 1697-1732. 
Torche, F. \& Shwed, U. (2015), 'The hidden costs of war: Exposure to armed conflict and birth outcomes', Sociological Science 2, 558-581.

Tukey, J. W. (1977), Exploratory data analysis, Vol. 2, Reading, MA.

United States Department of Health and Human Services (US DHHS), Centers for Disease Control and Prevention (CDC) (2018), 'National center for health statistics (NCHS), division of vital statistics, natality public-use data 2007-2017, on CDC WONDER online database, march 2009', pp. Accessed at http://wonder.cdc.gov/natality-current.html (data downloaded on 19 September 2019).

Van Der Aalst, W. (2016), Data science in action, in 'Process Mining', Springer, pp. 3-23.

Venkataramani, A. S., Bair, E., O’Brien, R. L. \& Tsai, A. C. (2019), 'Association between automotive assembly plant closures and opioid overdose mortality in the united states: A difference-in-differences analysis', JAMA Internal Medicine .

Walton, D. (2014), Abductive reasoning, University of Alabama Press.

West, S. G., Duan, N., Pequegnat, W., Gaist, P., Des Jarlais, D. C., Holtgrave, D., Szapocznik, J., Fishbein, M., Rapkin, B., Clatts, M. \& Mullen, P. D. (2008), 'Alternatives to the Randomized Controlled Trial', American Journal of Public Health 98(8), 1359-1366.

Yanai, I. \& Lercher, M. (2020), 'A hypothesis is a liability', Genome Biology 21(1), 231. URL: https://doi.org/10.1186/s13059-020-02133-w

Yu, C. H. (1994), 'Abduction? deduction? induction? is there a logic of exploratory data analysis?.'.

Zikopoulos, P. \& Eaton, C. (2011), Understanding Big Data: Analytics for Enterprise Class Hadoop and Streaming Data, McGraw-Hill Osborne Media. 


\title{
Supplementary Material
}

\author{
Matt Hauer \\ $9 / 16 / 2020$
}

Table 1: All Demographic Anoamlies detected.

\begin{tabular}{|c|c|c|c|c|c|c|}
\hline state & STATEID & component & time & type & tstat & coefhat \\
\hline $\mathrm{AL}$ & 01 & Fertility & 2008:11 & $\mathrm{AO}$ & -3.63526 & -476.0911 \\
\hline AL & 01 & Mortality & 2000:01 & $\mathrm{AO}$ & 5.12804 & 486.7737 \\
\hline $\mathrm{AL}$ & 01 & Mortality & 2000:03 & $\mathrm{TC}$ & -4.55360 & -470.9793 \\
\hline $\mathrm{AL}$ & 01 & Mortality & 2001:12 & $\mathrm{AO}$ & -3.62920 & -333.0932 \\
\hline $\mathrm{AL}$ & 01 & Mortality & 2003:12 & $\mathrm{AO}$ & 7.48327 & 660.4668 \\
\hline $\mathrm{AL}$ & 01 & Mortality & 2008:02 & $\mathrm{TC}$ & 4.45801 & 410.0415 \\
\hline $\mathrm{AL}$ & 01 & Mortality & 2013:01 & $\mathrm{AO}$ & 4.08582 & 363.8702 \\
\hline $\mathrm{AZ}$ & 04 & Fertility & $2005: 10$ & $\mathrm{AO}$ & -3.93621 & -580.0972 \\
\hline $\mathrm{AZ}$ & 04 & Fertility & 2008:03 & $\mathrm{LS}$ & -3.68783 & -457.7238 \\
\hline $\mathrm{AZ}$ & 04 & Mortality & 2003:12 & $\mathrm{AO}$ & 4.18375 & 454.8685 \\
\hline $\mathrm{AZ}$ & 04 & Mortality & 2005:12 & $\mathrm{TC}$ & 4.88077 & 654.6778 \\
\hline $\mathrm{AZ}$ & 04 & Mortality & 2016:02 & $\mathrm{LS}$ & 4.63373 & 555.4859 \\
\hline $\mathrm{AR}$ & 05 & Mortality & 2000:01 & $\mathrm{AO}$ & 4.28328 & 396.4951 \\
\hline $\mathrm{AR}$ & 05 & Mortality & 2003:12 & $\mathrm{AO}$ & 4.04010 & 287.6263 \\
\hline $\mathrm{AR}$ & 05 & Mortality & 2008:02 & $\mathrm{AO}$ & 5.08878 & 382.4616 \\
\hline $\mathrm{AR}$ & 05 & Mortality & 2013:01 & $\mathrm{AO}$ & 5.54341 & 409.2410 \\
\hline $\mathrm{AR}$ & 05 & Mortality & 2014:01 & $\mathrm{TC}$ & 3.52244 & 292.0337 \\
\hline $\mathrm{AR}$ & 05 & Mortality & $2017: 12$ & $\mathrm{AO}$ & 3.95242 & 359.8083 \\
\hline $\mathrm{CA}$ & 06 & Fertility & 2016:08 & $\mathrm{TC}$ & 3.66555 & 2203.5513 \\
\hline $\mathrm{CA}$ & 06 & Mortality & 2003:12 & $\mathrm{AO}$ & 4.39587 & 1987.4043 \\
\hline $\mathrm{CA}$ & 06 & Mortality & $2005: 12$ & $\mathrm{AO}$ & 4.12364 & 1807.0251 \\
\hline $\mathrm{CA}$ & 06 & Mortality & 2008:02 & $\mathrm{TC}$ & 4.94494 & 2602.4935 \\
\hline $\mathrm{CA}$ & 06 & Mortality & $2017: 12$ & $\mathrm{AO}$ & 3.72352 & 2151.3643 \\
\hline $\mathrm{CO}$ & 08 & Mortality & 2013:01 & $\mathrm{AO}$ & 3.53049 & 246.5604 \\
\hline $\mathrm{CO}$ & 08 & Mortality & 2015:02 & $\mathrm{TC}$ & -6.10508 & -578.7003 \\
\hline $\mathrm{CT}$ & 09 & Fertility & 2009:08 & $\mathrm{LS}$ & -3.71363 & -284.6775 \\
\hline $\mathrm{CT}$ & 09 & Mortality & $2003: 12$ & $\mathrm{AO}$ & 4.04637 & 296.2717 \\
\hline $\mathrm{CT}$ & 09 & Mortality & 2013:01 & $\mathrm{AO}$ & 3.74637 & 279.6102 \\
\hline $\mathrm{CT}$ & 09 & Mortality & 2014:02 & $\mathrm{LS}$ & 5.51927 & 139.8958 \\
\hline $\mathrm{CT}$ & 09 & Mortality & 2015:12 & $\mathrm{TC}$ & -3.75358 & -280.5957 \\
\hline $\mathrm{DE}$ & 10 & Mortality & 2012:11 & LS & 4.48328 & 88.7797 \\
\hline $\mathrm{DC}$ & 11 & Mortality & 2002:01 & $\mathrm{AO}$ & 4.84057 & 115.7816 \\
\hline FL & 12 & Mortality & 2000:03 & $\mathrm{AO}$ & -4.13081 & -1166.8559 \\
\hline FL & 12 & Mortality & $2003: 12$ & $\mathrm{TC}$ & 4.35066 & 1155.6626 \\
\hline GA & 13 & Mortality & 2003:12 & TC & 4.92570 & 638.9594 \\
\hline
\end{tabular}


Table 1: All Demographic Anoamlies detected. (continued)

\begin{tabular}{|c|c|c|c|c|c|c|}
\hline state & STATEID & component & time & type & tstat & coefhat \\
\hline GA & 13 & Mortality & 2008:02 & $\mathrm{TC}$ & 3.53556 & 445.0709 \\
\hline GA & 13 & Mortality & 2014:12 & $\mathrm{TC}$ & 4.61761 & 614.5234 \\
\hline HI & 15 & Fertility & 2014:05 & $\mathrm{AO}$ & 4.96017 & 226.2289 \\
\hline HI & 15 & Mortality & 2015:01 & $\mathrm{AO}$ & 3.63726 & 106.6684 \\
\hline ID & 16 & Fertility & 2008:01 & $\mathrm{TC}$ & 3.77381 & 179.1547 \\
\hline IL & 17 & Fertility & 2008:02 & $\mathrm{AO}$ & 3.50138 & 736.1977 \\
\hline IN & 18 & Mortality & 2003:12 & $\mathrm{AO}$ & 4.86247 & 667.1098 \\
\hline IN & 18 & Mortality & 2013:01 & $\mathrm{AO}$ & 5.89220 & 782.1618 \\
\hline IN & 18 & Mortality & 2015:01 & $\mathrm{AO}$ & 5.08068 & 719.9057 \\
\hline IA & 19 & Mortality & 2000:01 & $\mathrm{AO}$ & 4.22067 & 329.1083 \\
\hline IA & 19 & Mortality & 2003:12 & $\mathrm{TC}$ & 4.18714 & 318.6955 \\
\hline IA & 19 & Mortality & 2004:03 & $\mathrm{TC}$ & -4.84868 & -367.8987 \\
\hline IA & 19 & Mortality & 2013:01 & $\mathrm{AO}$ & 4.24874 & 304.9240 \\
\hline KS & 20 & Fertility & 2012:08 & $\mathrm{TC}$ & 4.86363 & 298.5049 \\
\hline KY & 21 & Mortality & 2000:01 & $\mathrm{AO}$ & 4.39043 & 407.5624 \\
\hline $\mathrm{KY}$ & 21 & Mortality & 2000:03 & $\mathrm{TC}$ & -4.04460 & -461.6888 \\
\hline $\mathrm{KY}$ & 21 & Mortality & 2003:12 & $\mathrm{TC}$ & 5.56447 & 555.6897 \\
\hline LA & 22 & Fertility & 2005:08 & $\mathrm{TC}$ & -6.00213 & -702.9202 \\
\hline LA & 22 & Fertility & 2005:10 & $\mathrm{TC}$ & -4.99691 & -620.4862 \\
\hline $\mathrm{ME}$ & 23 & Mortality & 2010:09 & LS & 5.05604 & 59.2778 \\
\hline ME & 23 & Mortality & 2015:01 & LS & 7.15573 & 99.5227 \\
\hline MD & 24 & Mortality & 2003:12 & $\mathrm{AO}$ & 3.95006 & 466.4458 \\
\hline MD & 24 & Mortality & 2015:02 & LS & 4.20150 & 286.7422 \\
\hline MA & 25 & Fertility & 2005:01 & $\mathrm{AO}$ & -3.93933 & -482.4588 \\
\hline MA & 25 & Mortality & 2000:01 & $\mathrm{AO}$ & 5.26608 & 656.1995 \\
\hline MA & 25 & Mortality & 2003:12 & $\mathrm{TC}$ & 4.59795 & 575.2061 \\
\hline MA & 25 & Mortality & 2004:02 & LS & -6.28503 & -302.4497 \\
\hline MA & 25 & Mortality & 2005:01 & $\mathrm{AO}$ & 4.78056 & 577.1766 \\
\hline MA & 25 & Mortality & 2006:03 & $\mathrm{TC}$ & 3.69979 & 453.4105 \\
\hline MA & 25 & Mortality & 2013:01 & $\mathrm{AO}$ & 6.16021 & 776.8701 \\
\hline MA & 25 & Mortality & 2015:01 & LS & 8.68608 & 444.6978 \\
\hline MA & 25 & Mortality & 2015:12 & $\mathrm{TC}$ & -4.16043 & -534.6610 \\
\hline MI & 26 & Mortality & 2000:01 & $\mathrm{AO}$ & 5.10046 & 882.6971 \\
\hline MI & 26 & Mortality & 2000:03 & $\mathrm{AO}$ & -4.54718 & -820.2133 \\
\hline MI & 26 & Mortality & 2008:02 & $\mathrm{TC}$ & 4.34279 & 830.4293 \\
\hline MI & 26 & Mortality & 2014:05 & LS & 5.54131 & 565.8971 \\
\hline $\mathrm{MN}$ & 27 & Mortality & 2000:02 & $\mathrm{TC}$ & -3.96853 & -405.9615 \\
\hline $\mathrm{MN}$ & 27 & Mortality & 2000:03 & $\mathrm{AO}$ & -3.65185 & -336.2720 \\
\hline $\mathrm{MN}$ & 27 & Mortality & 2004:03 & $\mathrm{AO}$ & -3.92523 & -340.5204 \\
\hline $\mathrm{MN}$ & 27 & Mortality & 2005:01 & $\mathrm{TC}$ & 4.56133 & 426.7506 \\
\hline MN & 27 & Mortality & 2013:01 & $\mathrm{AO}$ & 4.73263 & 401.8875 \\
\hline MS & 28 & Fertility & 2006:08 & $\mathrm{TC}$ & 4.29545 & 335.9598 \\
\hline MS & 28 & Mortality & 2000:01 & $\mathrm{AO}$ & 3.60022 & 328.1801 \\
\hline MS & 28 & Mortality & 2012:04 & LS & 11.13241 & 234.4396 \\
\hline MO & 29 & Mortality & 2000:01 & $\mathrm{AO}$ & 6.70617 & 829.4624 \\
\hline MO & 29 & Mortality & 2003:12 & $\mathrm{AO}$ & 5.72193 & 678.5393 \\
\hline
\end{tabular}


Table 1: All Demographic Anoamlies detected. (continued)

\begin{tabular}{|c|c|c|c|c|c|c|}
\hline state & STATEID & component & time & type & tstat & coefhat \\
\hline $\mathrm{MO}$ & 29 & Mortality & 2005:03 & $\mathrm{AO}$ & 3.64903 & 433.0229 \\
\hline MO & 29 & Mortality & 2008:02 & $\mathrm{TC}$ & 6.25163 & 738.5004 \\
\hline MO & 29 & Mortality & 2012:06 & LS & 7.44381 & 285.5670 \\
\hline $\mathrm{MO}$ & 29 & Mortality & 2016:04 & LS & 5.33701 & 276.1651 \\
\hline MT & 30 & Mortality & 2005:02 & $\mathrm{TC}$ & 4.56533 & 131.9953 \\
\hline MT & 30 & Mortality & 2016:12 & $\mathrm{TC}$ & 4.31327 & 136.2263 \\
\hline $\mathrm{NE}$ & 31 & Mortality & 2003:12 & $\mathrm{AO}$ & 4.61562 & 219.5569 \\
\hline $\mathrm{NE}$ & 31 & Mortality & 2004:03 & $\mathrm{TC}$ & -3.94876 & -185.1389 \\
\hline NV & 32 & Fertility & 2004:05 & $\mathrm{AO}$ & -3.75743 & -284.9307 \\
\hline $\mathrm{NH}$ & 33 & Fertility & 2008:02 & LS & -5.68403 & -75.5613 \\
\hline $\mathrm{NH}$ & 33 & Fertility & 2010:02 & LS & -5.38582 & -73.6777 \\
\hline $\mathrm{NH}$ & 33 & Mortality & 2010:04 & LS & 3.50759 & 49.1056 \\
\hline $\mathrm{NH}$ & 33 & Mortality & 2014:11 & LS & 6.68259 & 94.5200 \\
\hline NJ & 34 & Mortality & 2001:01 & $\mathrm{AO}$ & -5.25394 & -730.1265 \\
\hline NJ & 34 & Mortality & 2001:09 & $\mathrm{AO}$ & 5.70305 & 733.1479 \\
\hline NJ & 34 & Mortality & 2004:02 & LS & -4.16336 & -367.4317 \\
\hline NJ & 34 & Mortality & 2005:01 & $\mathrm{TC}$ & 4.06743 & 592.5153 \\
\hline NJ & 34 & Mortality & 2008:03 & $\mathrm{AO}$ & 3.70093 & 470.6901 \\
\hline NJ & 34 & Mortality & 2011:01 & $\mathrm{TC}$ & 3.67652 & 512.7843 \\
\hline NJ & 34 & Mortality & 2013:01 & $\mathrm{AO}$ & 6.68083 & 839.4441 \\
\hline NJ & 34 & Mortality & 2015:01 & $\mathrm{TC}$ & 3.88918 & 572.1396 \\
\hline NM & 35 & Mortality & 2008:02 & $\mathrm{AO}$ & 4.89007 & 232.9649 \\
\hline NY & 36 & Fertility & 2009:08 & LS & -3.81613 & -675.9306 \\
\hline NY & 36 & Fertility & 2013:02 & LS & -3.73425 & -685.2435 \\
\hline NY & 36 & Mortality & 2000:01 & $\mathrm{AO}$ & 5.90125 & 1523.4348 \\
\hline NY & 36 & Mortality & 2001:09 & $\mathrm{AO}$ & 6.39634 & 1627.5795 \\
\hline NY & 36 & Mortality & 2004:02 & LS & -5.59387 & -868.8630 \\
\hline NY & 36 & Mortality & 2005:01 & $\mathrm{AO}$ & 4.68886 & 1178.1655 \\
\hline NY & 36 & Mortality & 2008:02 & $\mathrm{TC}$ & 4.49333 & 1313.1883 \\
\hline NY & 36 & Mortality & 2013:01 & $\mathrm{AO}$ & 5.09972 & 1286.7644 \\
\hline NY & 36 & Mortality & 2015:01 & $\mathrm{TC}$ & 3.90770 & 1168.8950 \\
\hline $\mathrm{NC}$ & 37 & Mortality & 2000:01 & $\mathrm{AO}$ & 4.35640 & 638.6683 \\
\hline $\mathrm{NC}$ & 37 & Mortality & 2000:03 & $\mathrm{TC}$ & -4.13023 & -727.6876 \\
\hline $\mathrm{NC}$ & 37 & Mortality & 2003:12 & $\mathrm{AO}$ & 6.13518 & 792.9569 \\
\hline $\mathrm{NC}$ & 37 & Mortality & 2006:03 & $\mathrm{AO}$ & 3.62848 & 465.8942 \\
\hline $\mathrm{NC}$ & 37 & Mortality & 2012:04 & LS & 4.38439 & 418.6341 \\
\hline $\mathrm{NC}$ & 37 & Mortality & 2015:01 & LS & 5.43649 & 525.6793 \\
\hline $\mathrm{NC}$ & 37 & Mortality & 2017:03 & $\mathrm{AO}$ & 3.94487 & 574.9178 \\
\hline $\mathrm{OH}$ & 39 & Mortality & 2000:01 & $\mathrm{AO}$ & 5.73968 & 1097.0115 \\
\hline $\mathrm{OH}$ & 39 & Mortality & 2000:03 & $\mathrm{TC}$ & -3.63496 & -868.3683 \\
\hline $\mathrm{OH}$ & 39 & Mortality & 2003:12 & $\mathrm{TC}$ & 6.90558 & 1528.0049 \\
\hline $\mathrm{OH}$ & 39 & Mortality & 2005:03 & $\mathrm{AO}$ & 4.31174 & 812.7438 \\
\hline $\mathrm{OH}$ & 39 & Mortality & 2008:02 & $\mathrm{TC}$ & 3.57092 & 773.9587 \\
\hline $\mathrm{OH}$ & 39 & Mortality & 2013:01 & $\mathrm{AO}$ & 6.81518 & 1250.7794 \\
\hline $\mathrm{OH}$ & 39 & Mortality & 2015:02 & LS & -4.26921 & -1157.3393 \\
\hline OK & 40 & Mortality & 2000:01 & $\mathrm{AO}$ & 6.53041 & 564.1853 \\
\hline
\end{tabular}


Table 1: All Demographic Anoamlies detected. (continued)

\begin{tabular}{|c|c|c|c|c|c|c|}
\hline state & STATEID & component & time & type & tstat & coefhat \\
\hline OK & 40 & Mortality & 2003:12 & $\mathrm{AO}$ & 6.12829 & 484.7089 \\
\hline OK & 40 & Mortality & 2008:02 & $\mathrm{AO}$ & 5.72159 & 453.1802 \\
\hline OK & 40 & Mortality & 2013:01 & LS & 5.88299 & 240.6262 \\
\hline OR & 41 & Fertility & 2005:02 & $\mathrm{AO}$ & -3.52100 & -309.3496 \\
\hline OR & 41 & Mortality & 2000:01 & $\mathrm{AO}$ & 4.45571 & 292.0508 \\
\hline OR & 41 & Mortality & 2003:12 & $\mathrm{AO}$ & 3.64746 & 238.8606 \\
\hline OR & 41 & Mortality & 2013:01 & $\mathrm{TC}$ & 4.11413 & 289.2114 \\
\hline OR & 41 & Mortality & 2017:01 & $\mathrm{AO}$ & 6.98586 & 478.7094 \\
\hline $\mathrm{PA}$ & 42 & Fertility & 2008:02 & $\mathrm{AO}$ & 3.78262 & 704.6169 \\
\hline $\mathrm{PA}$ & 42 & Mortality & 2000:01 & $\mathrm{AO}$ & 5.21016 & 1287.6043 \\
\hline $\mathrm{PA}$ & 42 & Mortality & 2003:12 & $\mathrm{TC}$ & 6.34267 & 1556.3416 \\
\hline PA & 42 & Mortality & 2005:02 & $\mathrm{TC}$ & 3.75053 & 995.8809 \\
\hline $\mathrm{PA}$ & 42 & Mortality & 2008:02 & $\mathrm{TC}$ & 4.35277 & 1092.9297 \\
\hline $\mathrm{PA}$ & 42 & Mortality & 2013:01 & $\mathrm{AO}$ & 4.10701 & 939.2149 \\
\hline $\mathrm{RI}$ & 44 & Mortality & 2000:01 & $\mathrm{AO}$ & 4.87114 & 207.5642 \\
\hline RI & 44 & Mortality & 2005:01 & $\mathrm{TC}$ & 4.13923 & 155.9976 \\
\hline $\mathrm{SC}$ & 45 & Mortality & 2000:03 & $\mathrm{TC}$ & -4.18260 & -395.5357 \\
\hline $\mathrm{SC}$ & 45 & Mortality & 2003:12 & TC & 4.95743 & 428.4264 \\
\hline $\mathrm{SC}$ & 45 & Mortality & 2005:02 & $\mathrm{TC}$ & 4.99622 & 449.9698 \\
\hline $\mathrm{SC}$ & 45 & Mortality & 2008:02 & $\mathrm{TC}$ & 3.84015 & 346.2581 \\
\hline $\mathrm{SC}$ & 45 & Mortality & 2011:12 & $\mathrm{TC}$ & -4.33533 & -386.8461 \\
\hline $\mathrm{SC}$ & 45 & Mortality & 2016:02 & $\mathrm{AO}$ & 4.00147 & 360.7129 \\
\hline $\mathrm{TN}$ & 47 & Mortality & 2000:01 & $\mathrm{AO}$ & 3.87715 & 515.2153 \\
\hline $\mathrm{TN}$ & 47 & Mortality & 2003:12 & $\mathrm{AO}$ & 5.97624 & 757.8804 \\
\hline $\mathrm{TN}$ & 47 & Mortality & 2008:02 & $\mathrm{AO}$ & 3.60115 & 449.4722 \\
\hline $\mathrm{TX}$ & 48 & Mortality & 2000:01 & $\mathrm{AO}$ & 5.77140 & 1784.2714 \\
\hline $\mathrm{TX}$ & 48 & Mortality & 2002:01 & $\mathrm{TC}$ & 5.28612 & 1481.2292 \\
\hline $\mathrm{TX}$ & 48 & Mortality & 2005:02 & $\mathrm{TC}$ & 4.62638 & 1310.8300 \\
\hline $\mathrm{TX}$ & 48 & Mortality & 2008:02 & $\mathrm{AO}$ & 5.04507 & 1441.3564 \\
\hline TX & 48 & Mortality & 2013:01 & $\mathrm{AO}$ & 7.13433 & 1949.1723 \\
\hline $\mathrm{TX}$ & 48 & Mortality & 2014:01 & $\mathrm{AO}$ & 4.47608 & 1229.5101 \\
\hline $\mathrm{TX}$ & 48 & Mortality & 2015:01 & $\mathrm{AO}$ & 5.89546 & 1670.5812 \\
\hline $\mathrm{UT}$ & 49 & Mortality & 2003:12 & $\mathrm{AO}$ & 4.18091 & 168.9354 \\
\hline $\mathrm{VT}$ & 50 & Fertility & 2005:07 & $\mathrm{TC}$ & -4.85815 & -104.7377 \\
\hline VT & 50 & Mortality & 2000:01 & $\mathrm{AO}$ & 4.19129 & 99.3281 \\
\hline $\mathrm{VT}$ & 50 & Mortality & 2001:06 & $\mathrm{TC}$ & 3.61313 & 70.8473 \\
\hline $\mathrm{VT}$ & 50 & Mortality & 2008:01 & $\mathrm{AO}$ & -4.11211 & -89.2642 \\
\hline VA & 51 & Mortality & 2003:12 & $\mathrm{AO}$ & 7.05760 & 919.4141 \\
\hline VA & 51 & Mortality & 2006:03 & $\mathrm{AO}$ & 3.96012 & 508.3156 \\
\hline WA & 53 & Mortality & 2003:12 & $\mathrm{AO}$ & 4.53139 & 487.4918 \\
\hline WA & 53 & Mortality & 2017:01 & $\mathrm{TC}$ & 6.00615 & 724.6422 \\
\hline WV & 54 & Mortality & 2000:01 & $\mathrm{AO}$ & 3.92141 & 258.4560 \\
\hline WV & 54 & Mortality & 2003:12 & $\mathrm{AO}$ & 5.38802 & 338.7782 \\
\hline WV & 54 & Mortality & 2012:04 & LS & 5.31478 & 106.9373 \\
\hline WI & 55 & Fertility & 2008:02 & $\mathrm{AO}$ & 3.65776 & 422.4784 \\
\hline WI & 55 & Mortality & 2000:01 & $\mathrm{AO}$ & 3.86741 & 445.4985 \\
\hline
\end{tabular}


Table 1: All Demographic Anoamlies detected. (continued)

\begin{tabular}{lllllrr}
\hline state & STATEID & component & time & type & tstat & coefhat \\
\hline WI & 55 & Mortality & $2005: 02$ & AO & 4.72419 & 536.8851 \\
WI & 55 & Mortality & $2008: 02$ & TC & 3.52011 & 379.2764 \\
WI & 55 & Mortality & $2012: 07$ & LS & 5.84049 & 345.4592 \\
WI & 55 & Mortality & $2013: 01$ & AO & 5.73090 & 638.0866 \\
WY & 56 & Mortality & $2002: 01$ & AO & 3.71787 & 89.7037 \\
\hline
\end{tabular}



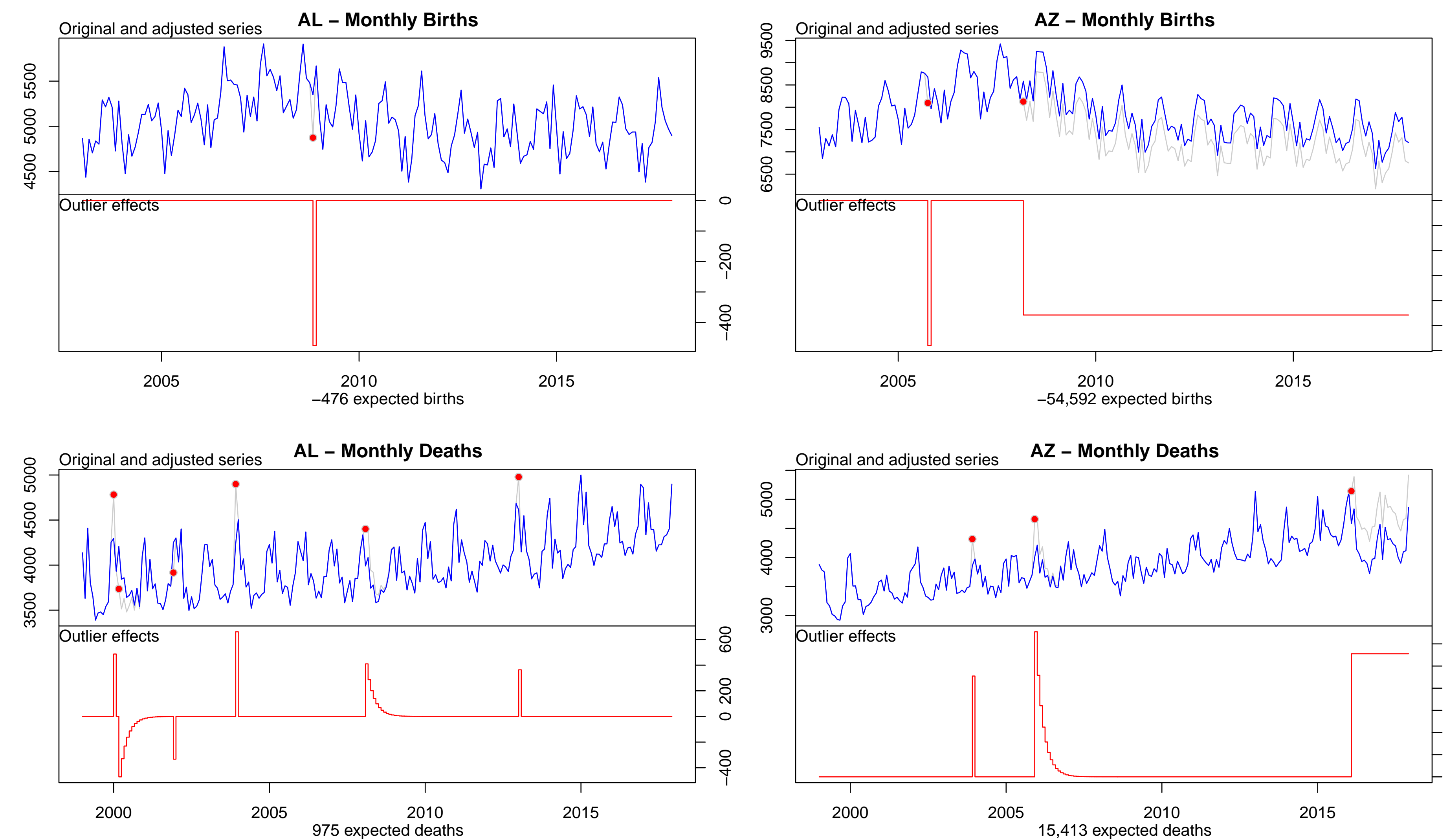

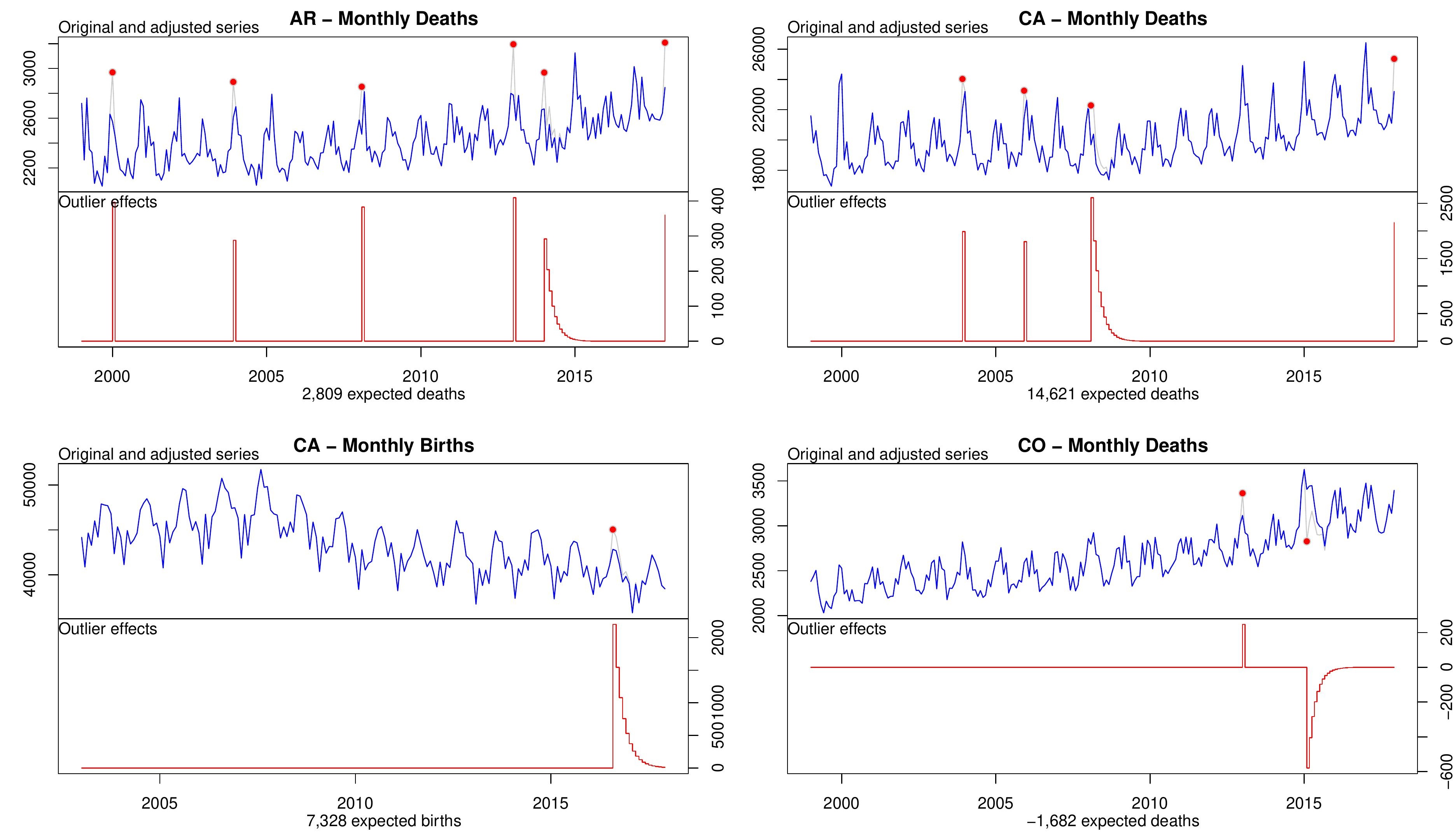

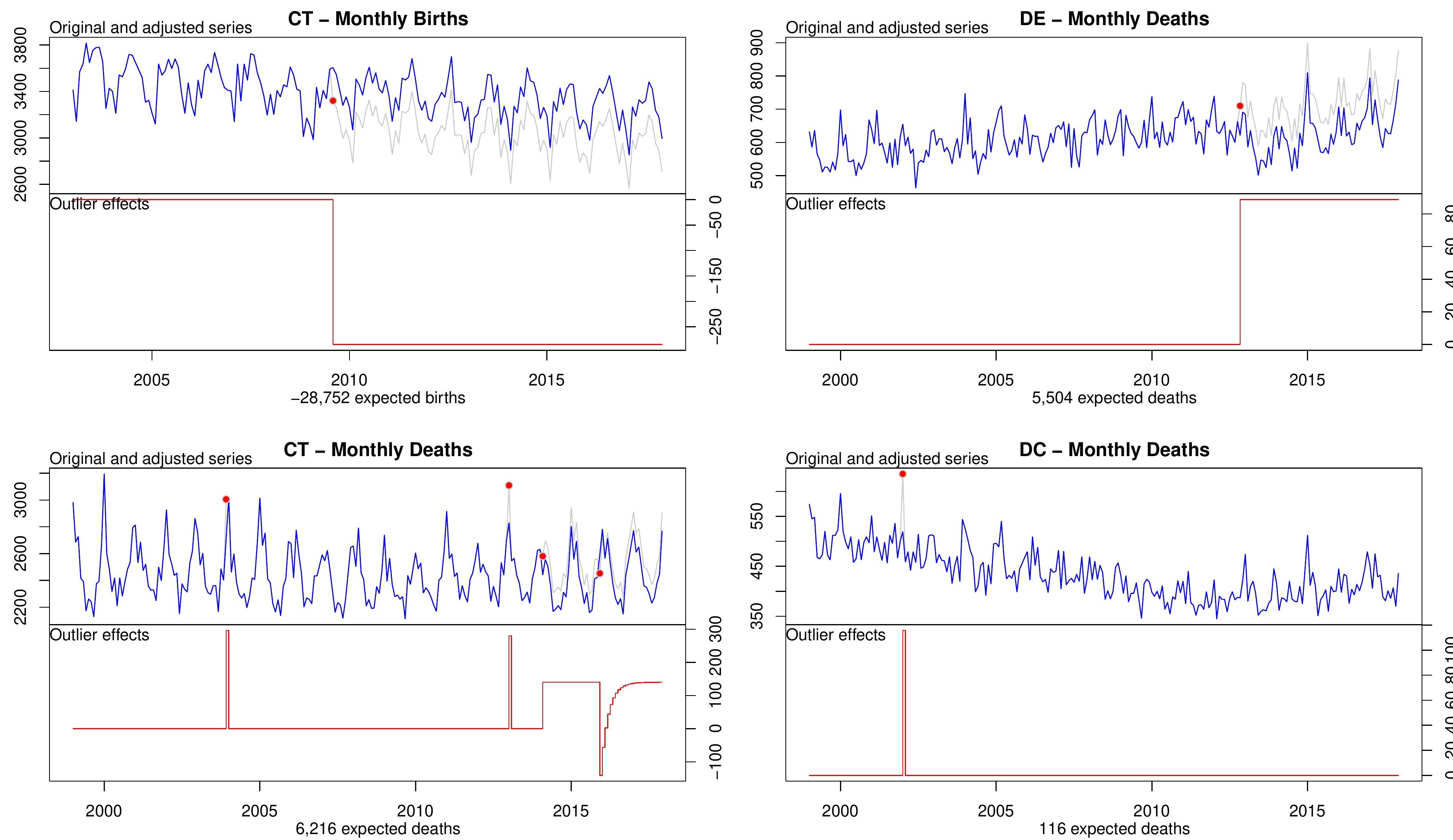

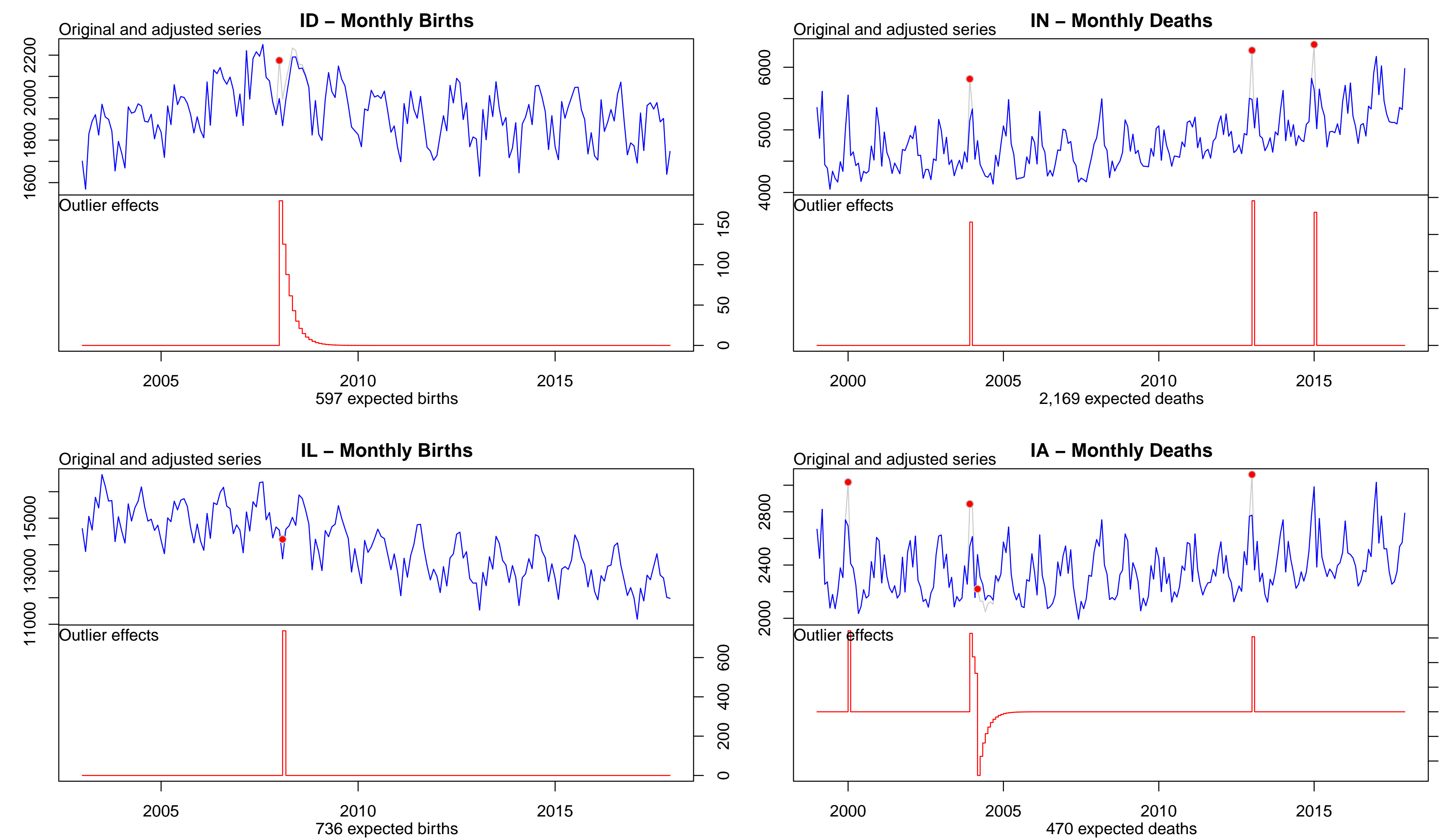

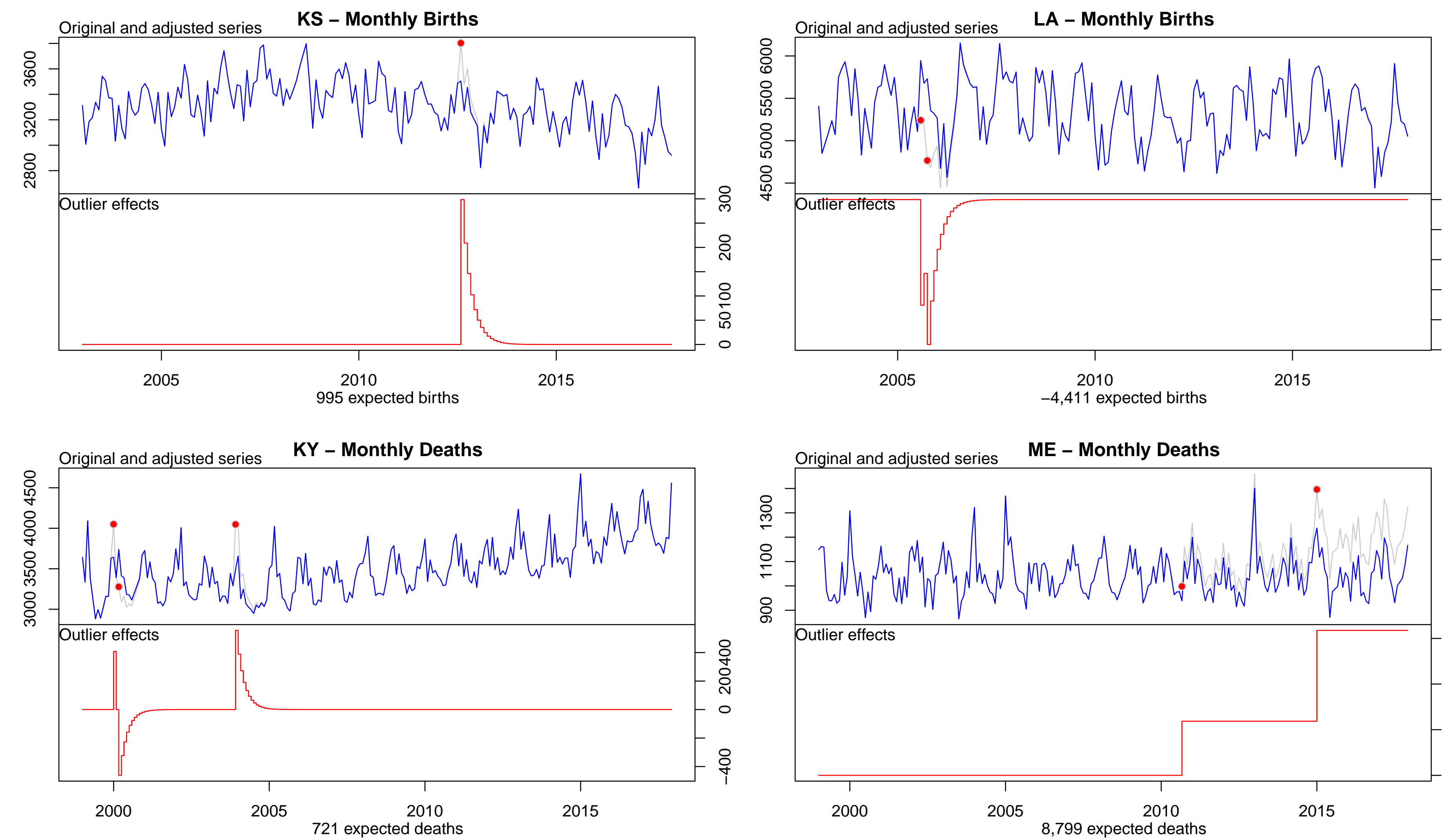

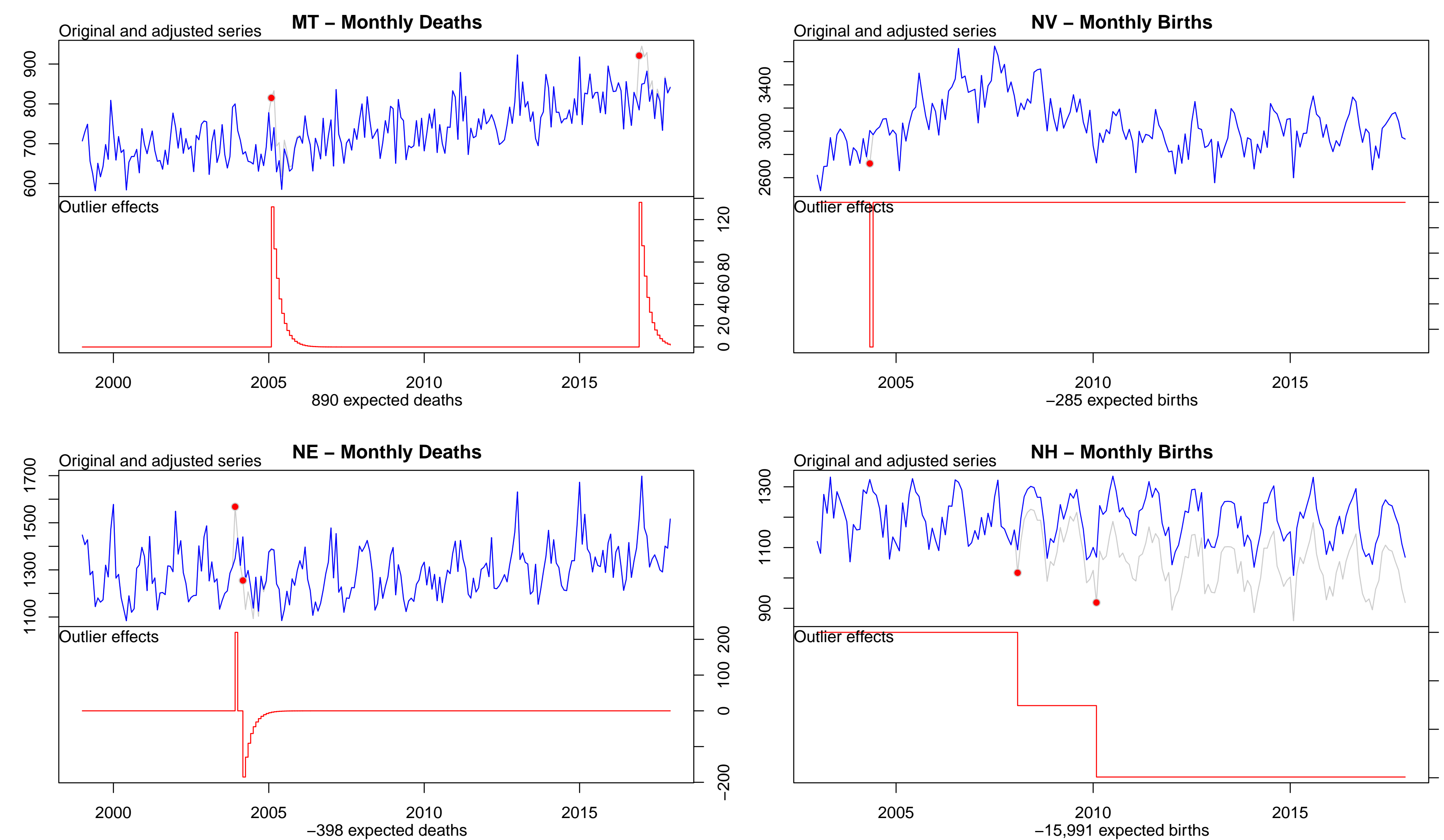

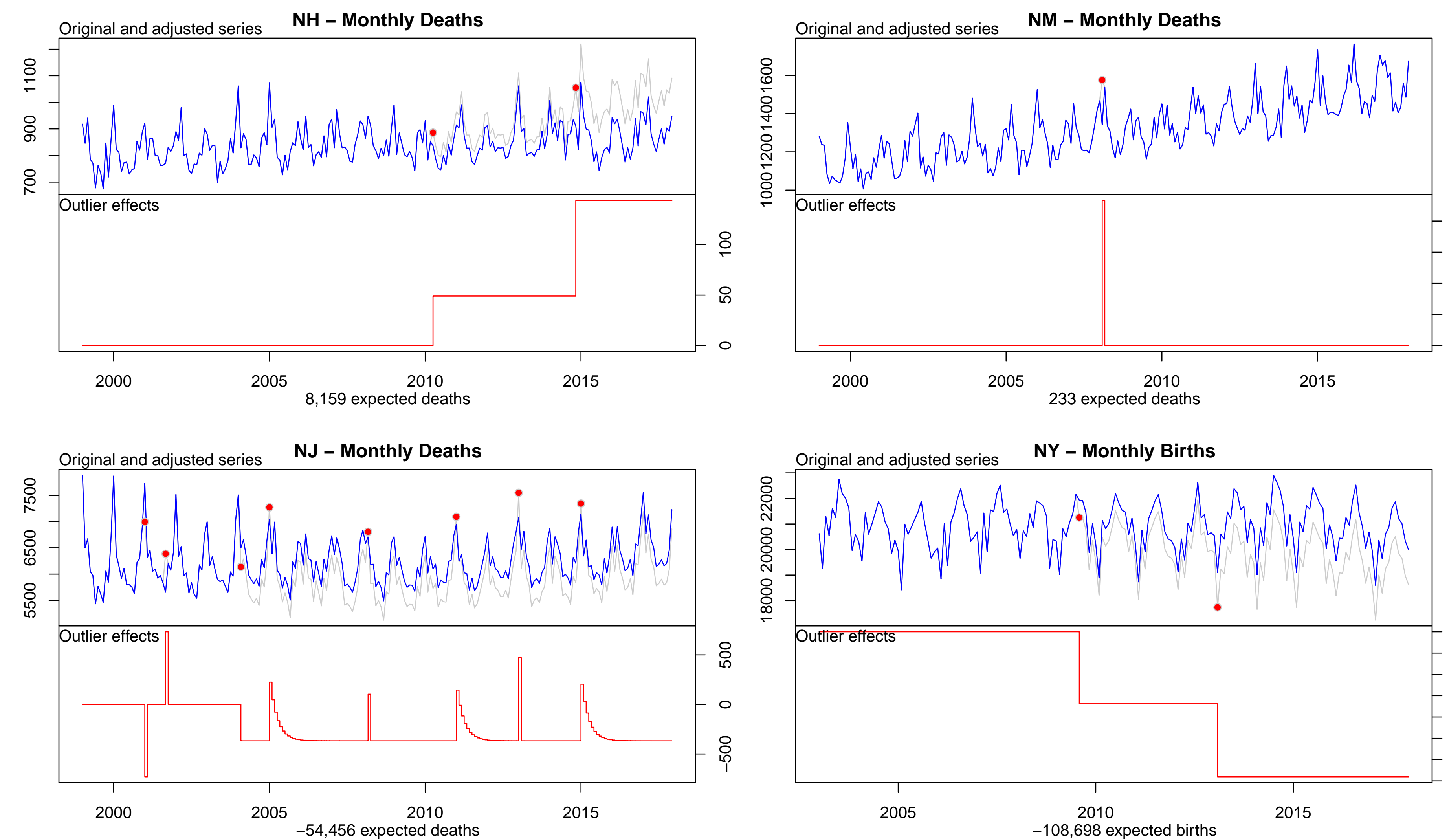

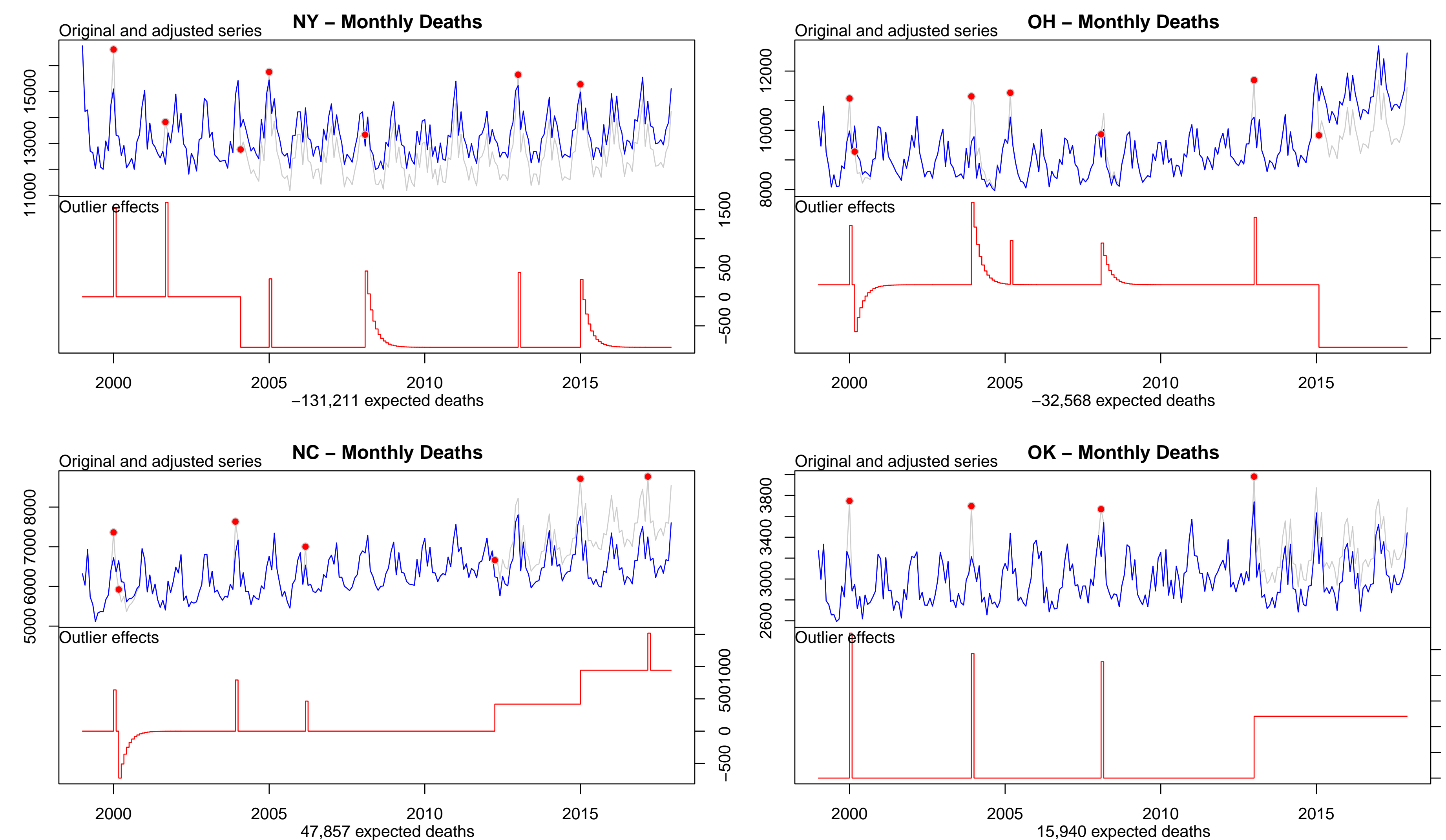

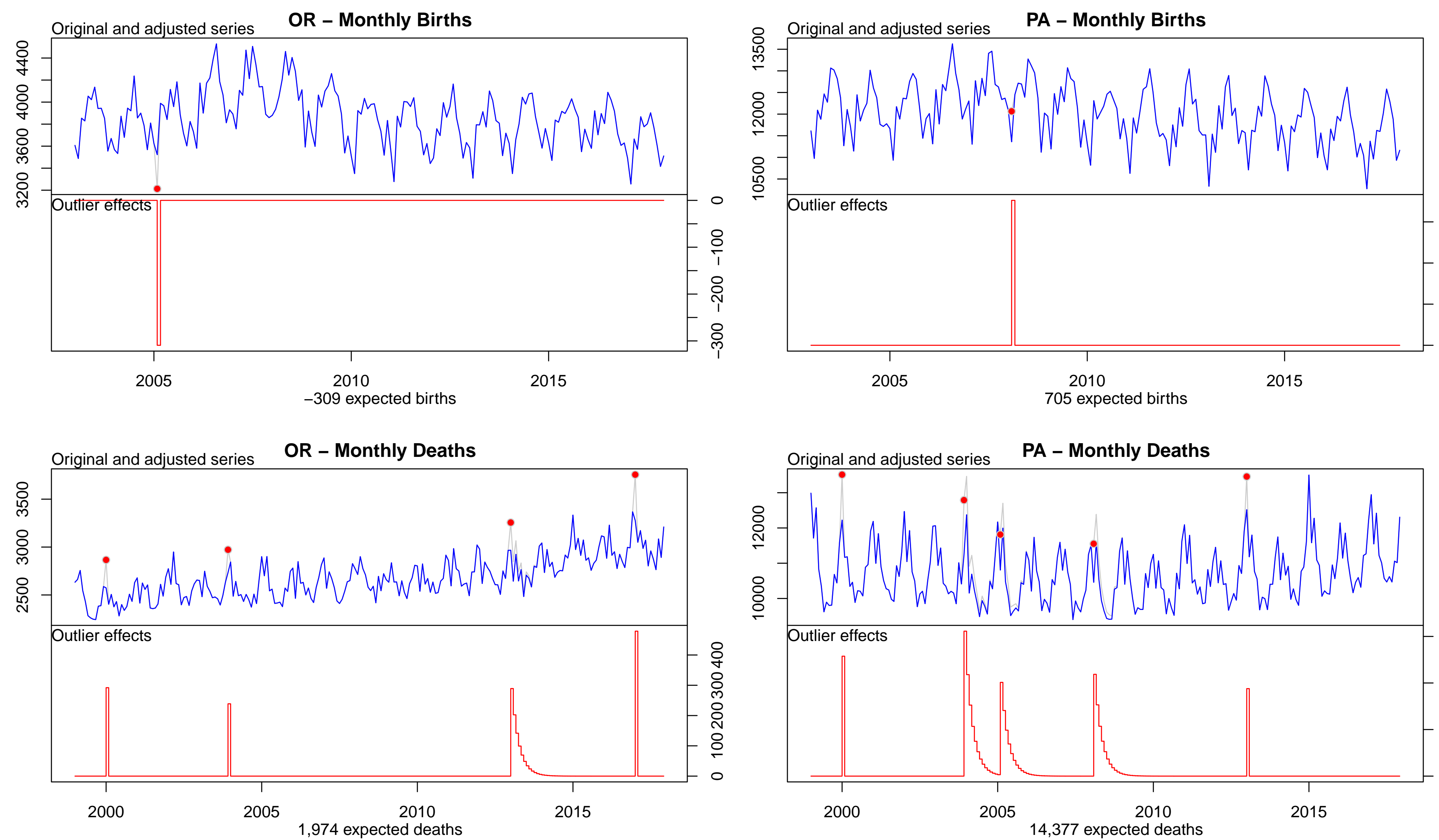

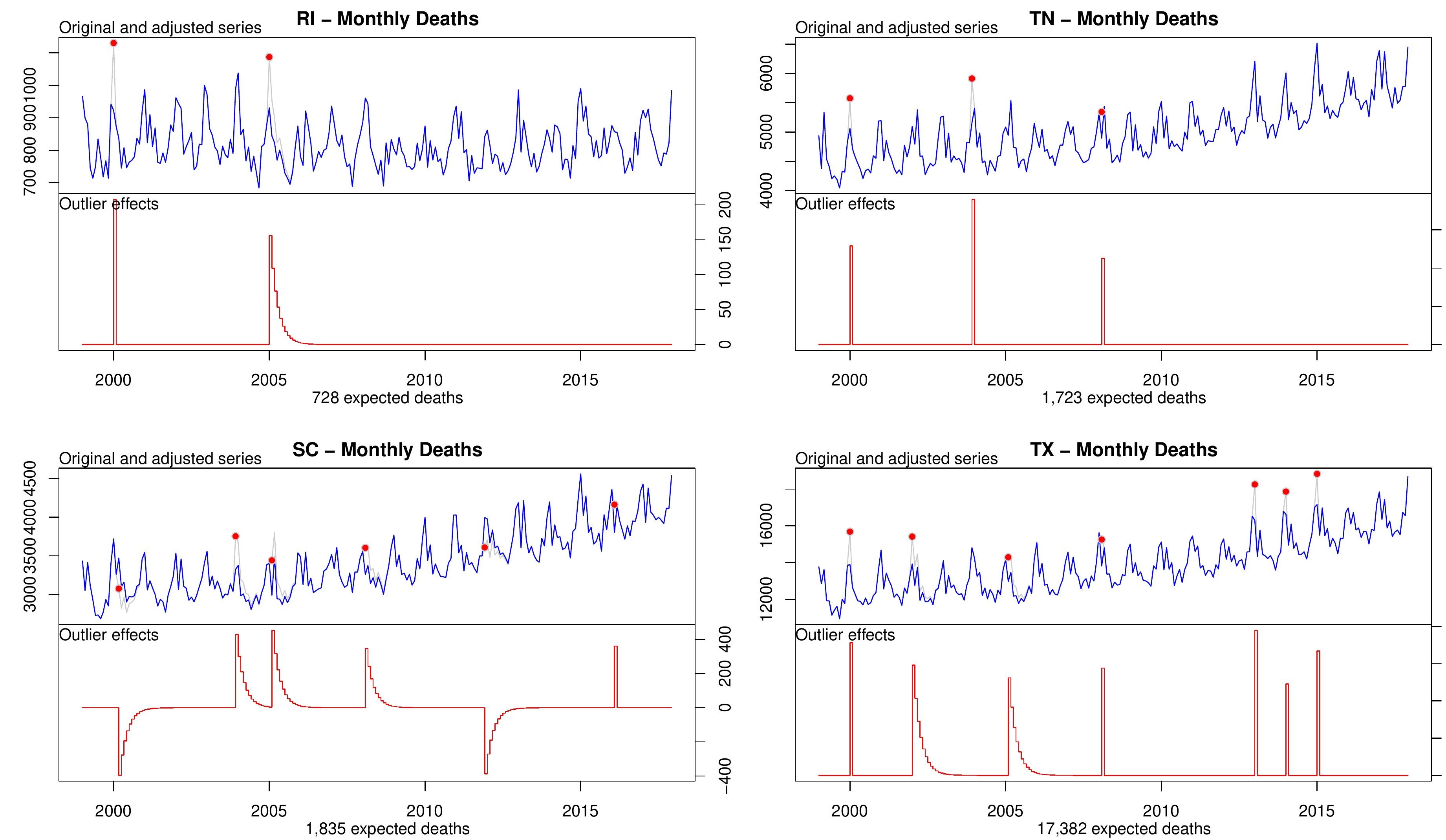

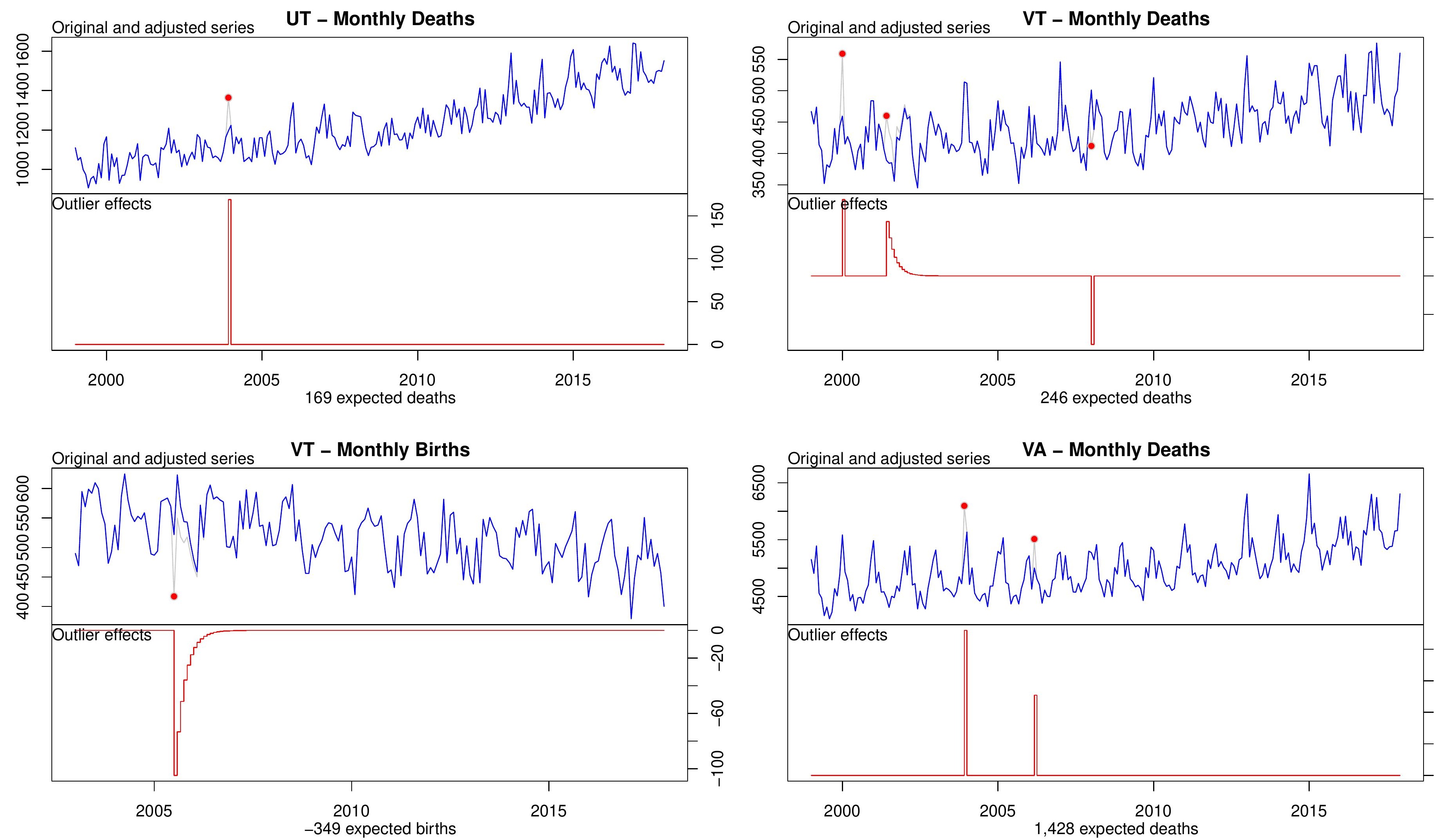

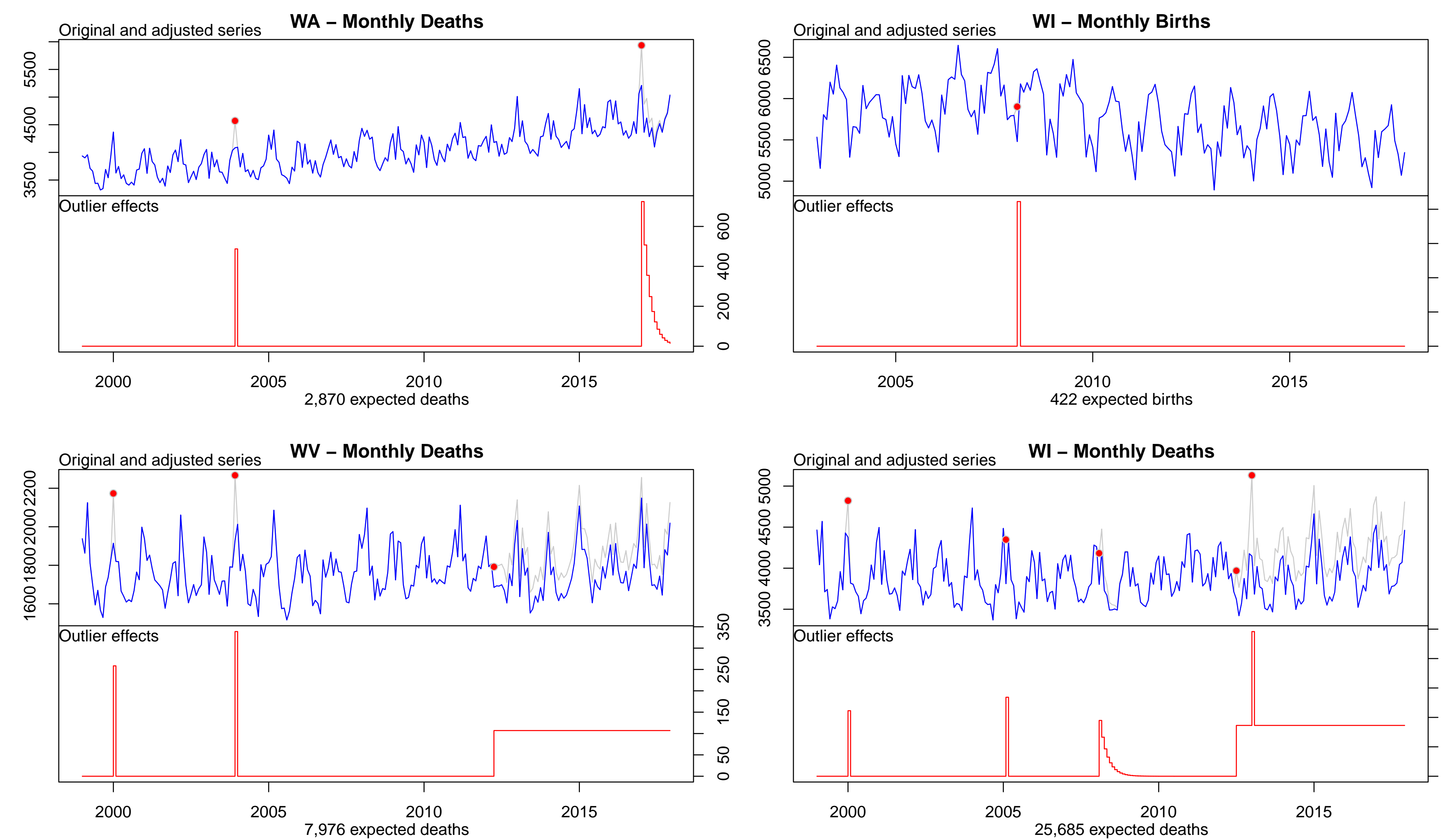


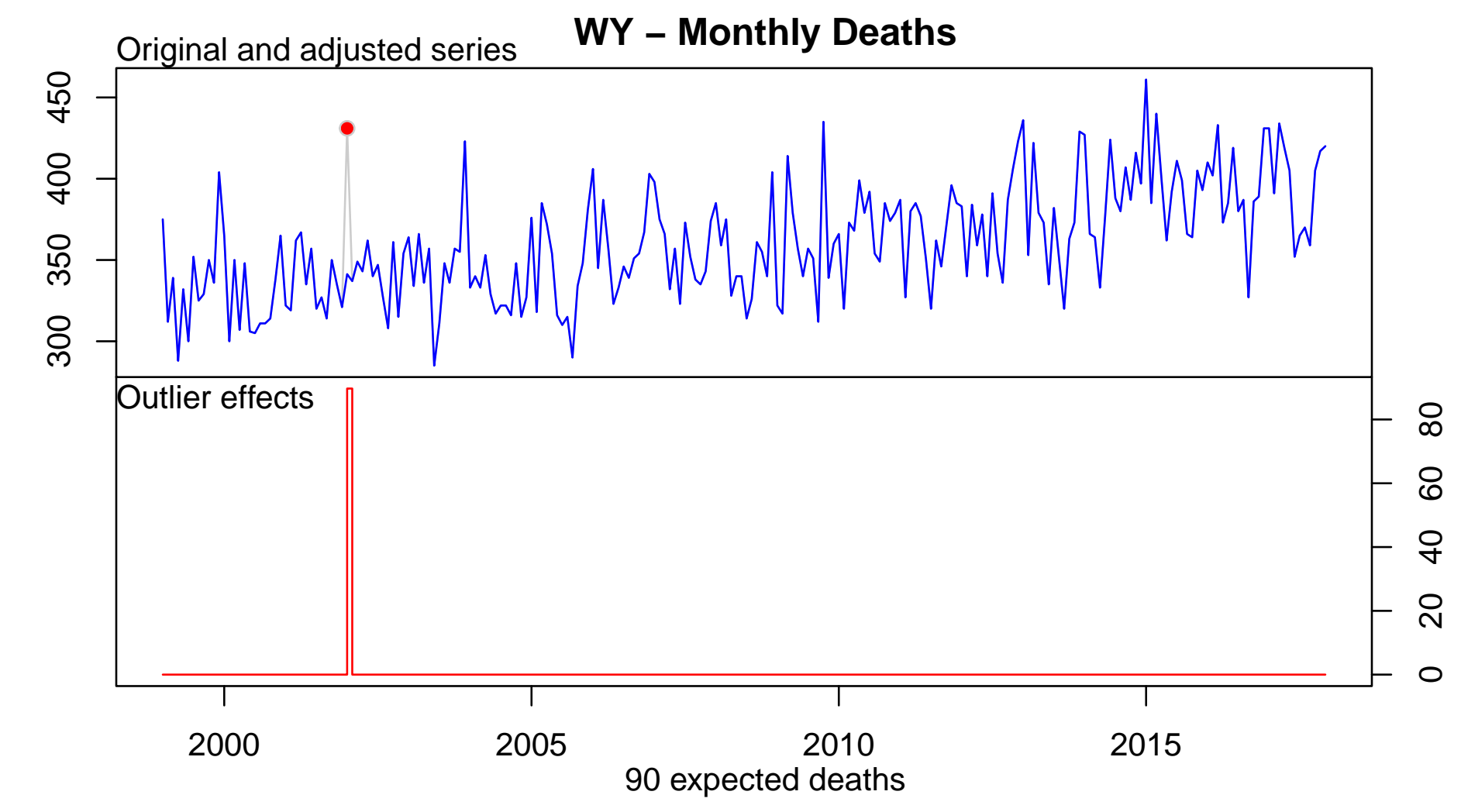

